\title{
An Analysis of Isostasy in the World's Oceans 2. Midocean Ridge Crests
}

\author{
J. R. COCHRAN
}

\author{
Lamont-Doherty Geological Observatory of Columbia University. Palisades, New York 10964
}

\begin{abstract}
Cross-spectral techniques are used to analyze the relationship between gravity and bathymetry at the Mid-A tlantic Ridge and the East Pacific Rise crests. The resulting transfer functions were used to study the nature of the isostatic mechanism operative at these ridge crests. The most satisfactory results were obtained for models in which the oceanic lithosphere is treated as a thin elastic plate overlying a weak fluid. The best fitting elastic thickness to explain gravity and bathymetry at the fast spreading $(v>5 \mathrm{~cm} /$ yr) East Pacific Rise is in the range of $2-6 \mathrm{~km}$ and at the relatively slow spreading $(v<2 \mathrm{~cm} / \mathrm{yr}) \mathrm{Mid}$ Atlantic Ridge is in the range $7-13 \mathrm{~km}$. These estimates are significantly smaller than the elastic thickness of 20-30 km obtained from surface loads formed on old $(>80 \mathrm{~m} . \mathrm{y}$.) parts of the oceanic lithosphere. This difference is consistent with the fact that ridge topography is formed near the ridge axis, where isotherms are shallower and the lithosphere is thus weaker than in older regions. The difference between the elastic thickness of the East Pacific Rise and Mid-Atlantic Ridge is significant and may represent differing temperature structures at these ridges. Simple models in which it is assumed that the elastic thickness represents the depth to the $450^{\circ} \mathrm{C}$ isotherm show that these variations can be explained by differences in the spreading rate at these ridges. Thus the lower effective thickness at the East Pacific Rise can be attributed to higher average temperatures at shallow depths in a region surrounding the ridge crest. This is due to the faster spreading rate which results in isotherms having a shallower dip away from the axis than at the slower spreading Mid-A tlantic Ridge. This model cannot, however, explain gravity and bathymetry data over the Rekyjanes Ridge. The best fitting elastic thickness for this slow spreading ridge is similar to the thickness determined for the East Pacific R ise, suggesting an anomalous thermal regime at this ridge crest.
\end{abstract}

\section{INTRODUCTION}

Midocean ridges are recognized in plate tectonic theory as the site of creation of oceanic lithosphere which subsequently evolves through cooling and the solidification of hot mantle material. Simple models have been constructed for the cooling lithosphere which generally explain the regional topography, heat flow, and free air gravity anomalies over ridge crests [Sclater and Francheteau, 1970; Parker and Oldenburg. 1973; Lambeck, 1972]. These models have been mainly concerned with explaining the evolution of the lithosphere away from the ridge crest and therefore provide little information on subsurface processes occurring at the ridge axis.

A number of models have now been constructed which attempt to explain the character of sea floor topography at the ridge axis. One class of model considers the viscous interaction between the ascending hot mantle material and the adjoining lithosphere [Sleep, 1969, 1975; Sleep and Rosendahl, 1979; Sleep and Biehler. 1970; Osmaston, 1971; Lachenbruch, 1973, 1976; Rea, 1975]. The other considers the imbalance between the width over which hot mantle material is intruded and the distance which is required for newly erupted material to reach the mean half spreading rate [Deffeyes, 1970; Anderson and Noltimier, 1973]. Both classes of models appear able to explain the general observation that slower spreading ridges $(u$ is less than about $3 \mathrm{~cm} / \mathrm{yr}$ ) are characterized by an axial rift valley, while faster spreading ridges $(u$ is greater than about $3 \mathrm{~cm} / \mathrm{yr}$ ) are characterized by an axial 'block' or 'horst.'

Two studies which have provided useful observational constraints on midocean ridge crest processes are the FrenchAmerican Mid-Ocean Undersea Study (Famous) project on the Mid-Atlantic Ridge and a series of ocean bottom seismometer (OBS) studies on the East Pacific Rise crest. Project Famous involved extensive surface ship and deep tow measurements as well as bottom sampling from submersibles [e.g.,

Copyright (c) 1979 by the American Geophysical Union.
Needham and Francheteau, 1974; Arcyana, 1975; Heirtzler and Van A ndel, 1977] and provided new information on the morphology and tectonics of the slow spreading Mid-Atlantic Ridge [e.g., Ballard and Van Andel, 1977; Ramberg and Van Andel, 1977; Bryan and Moore, 1977; McDonald and Luyendyk. 1977]. The OBS studies [e.g., Orcutt et al., 1976; Rosendahl et al., 1976] have revealed a low-velocity zone at very shallow depths beneath the East Pacific Rise crest which may represent a zone of partial melt or a magma reservoir for the basaltic magmas erupted at the ridge axis [Rosendahl, 1976; Cann, 1974].

A though these studies have greatly increased the knowledge of subsurface processes occurring at the ridge axis, there are a number of problems which need to be resolved. These include the origin of ridge crest topography, the causes of variations in the type of axial topography between ridge crests, and whether or not a low-velocity zone underlies all ridge crests.

A useful approach to some of these problems can be made from studies of the relationship of gravity and bathymetry over ridge crests. The empirical age against depth curve [Sclater et al., 1971] describes the systematic increase in sea floor depth away from the ridge crest. However, on a local scale there are significant deviations from the empirical curve associated with topographic relief. These have dimensions of a few kilometers to a hundred or more kilometers and amplitudes of a few hundred meters to a few kilometers. The gravity anomalies associated with short-wavelength topographic irregularities are greatly reduced when a Bouguer correction is made [Talwani et al., 1961, 1965], implying that they must be supported by the strength of the lithosphere [Vening Meinesz, 1948]. A number of recent studies suggest that ridge flank topography is created at or near the ridge axis and is subsequently 'frozen in' and transported away as the lithosphere thickens and cools [e.g., Needham and Francheteau, 1974; McDonald and Luyendyk, 1977]. The relationship between gravity and bathymetry over ridge flanks may therefore pro- 
vide information on subsurface processes occurring at the ridge axis.

Most previous studies of the gravity field over midocean ridges have been concerned with the manner in which the ridge flanks are supported and thus have been concerned with the interpretation of long-wavelength gravity anomalies. Talwani et al. [1961, 1965] analyzed the first continuous gravity profiles across the Mid-Atlantic Ridge and East Pacific Rise. They found that the ridge crest was associated with relatively small positive free air gravity anomalies and a Bouguer gravity anomaly low of about $140 \mathrm{mGal}$ relative to the values in the ocean basins. This anomaly, which has a width of about 1600 $\mathrm{km}$ in the North Atlantic [Talwani et al., 1965], was interpreted as being caused by low-density material underlying the ridge flanks and providing compensation for the ridge. Recently, Cochran and Talwani [1977] have shown that the ridge crest is in general associated with a free air anomaly gravity high of $20-30 \mathrm{mGal}$ similar to that expected from simple thermal models of a cooling lithosphere [Sclater and Francheteau, 1970; Parker and Oldenberg, 1973].

Although many investigators [Talwani et al., 1961, 1965, 1971; Van Andel and Bowin, 1968; Woodside. 1972] have recognized that short-wavelength free air gravity anomalies with amplitudes of up to $\pm 50 \mathrm{mGal}$ exist over ridge crests, there have been only a few attempts to interpret them quantitatively. Woodside [1972] argued from a break in slope of the Bouguer gravity versus depth relationship that the rift mountains are supported by tectonic forces and/or a lower mantle density beneath the crest of the ridge. Talwani et al. [1972] examined the relationship between gravity and bathymetry on a profile across the Mid-A tlantic Ridge at $32^{\circ} \mathrm{N}$ and concluded that the gravity anomalies could be well predicted from uncompensated topographic relief, at least for wavelengths of up to a few hundred kilometers.

Recently, McKenzie and Bowin [1976] examined the relationship between gravity and bathymetry along two long profiles, one of which crossed the Mid-Atlantic Ridge at about $10^{\circ} \mathrm{N}$. They used Wiener filter and cross-spectral techniques to quantitatively determine the relationship between gravity anomalies and bathymetric relief. They concluded that their results could best be explained by an elastic plate model of compensation, in which the plate thickness is about $10 \mathrm{~km}$. They noted that this effective elastic thickness is much less than previous determinations [Walcott, 1970; Watts and Cochran, 1974] from loads on relatively old portions of the oceanic lithosphere and that this difference could be explained if the topography were created near the ridge crest, where isotherms are higher in the mantle.

The purpose of this paper is to examine the relationship between gravity and bathymetry over midocean ridge crests which differ in tectonic setting and spreading rate. We will use the cross-spectral techniques of analyzing gravity and bathymetry data described in paper 1 [Watts, 1978]. The resulting transfer functions or filters will be interpreted in terms of different models of isostasy at ridge crests. This analysis will enable us to provide new constraints on the subsurface process operating at ridge crests and to examine the causes of differences between these processes at various ridge crests.

\section{Data Collection, Reduction, and Presentation}

In this study we have used surface-ship gravity and bathymetry profiles over midocean ridge crests, obtained mainly on United States research vessels during the past 15 years. The sources of the data are (1) Lamont-Doherty Geological Obser- vatory of Columbia University for $R / V$ Vema cruises 17-24, 26, 28, 32 (1961-1974); R/V Robert D. Conrad cruises 8, 1013, 17, 20 (1963-1976); and USNS Eltanin cruise: 29 (1967), (2) Hydrographic Office of the Royal Netherlands Navy for HMNS Snellius cruises (1965-1966) (W. Langeraar, personal communication, 1966), (3) Woods Hole Oceanographic Institution for R/V Chain cruise 100 (1971) (data obtained from National Geophysical and Solar-Terrestrial Data Center), and (4) Pacific Marine Environmental Laboratory (formerly Pacific Oceanographic Laboratory, POL) for USS Oceanographer cruises (1971-1972) (data obtained from National Geophysical and Solar-Terrestrial Data Center).

The instruments and navigation used for the various gravity surveys differed. The Lamont-Doherty and R oyal Netherlands Navy data were obtained with G raf-Askania Gss2 sea gravimeters [Graf and Schulze, 1961]. Different platforms were used with this meter. The Royal Netherlands Navy data and Lamont-Doherty data obtained on USNS Eltanin and cruises of R/V Vema and R/V Robert D. Conrad prior to 1972 (Vema, cruise 29; Robert D. Conrad, cruise 15) utilized either an oil or electrically erected Anschütz gyrotable. Since 1972, measurements on R/V Vema and R/V Robert D. Conrad have been obtained on an A eroflex platform. This platform differs from the Anschütz platform mainly in the vertical reference which consists of miniature integrating gyroscopes in the pitch and roll axes to slave the platform and by the fact that torque motors rather than gear trains drive the platform. The Woods Hole data were obtained with the MIT sea gravimeter which utilizes a double-string Bosch-Arma type accelerometer [Wing, 1969] mounted on a Sperry gyrotable. The Pacific Marine Environmental Laboratory data were obtained with a gimbalmounted LaCoste-Romberg sea gravimeter [LaCoste, 1967]. Most of the data used in this study were obtained with satellite navigation. Only Lamont-Doherty cruises prior to 1967 (Vema, cruise 23, Robert D. Conrad, cruise 11) and the Royal Netherlands Navy cruise used celestial navigation.

The overall accuracy of the gravity measurements obtained during these surveys is affected by the accuracy of the gravimeter and the navigation. In general, those cruises which used the Gss2 sea gravimeter or the MIT instrument with satellite navigation should be accurate to about 2-5 mGal. However, somewhat larger errors would be expected for cruises which used the gimbal-mounted LaCoste-Romberg gravimeter or celestial navigation.

The gravity anomalies which we used were reduced to the international reference ellipsoid (flattening equal to $1 / 297.0$ ). However, the choice of a reference ellipsoid is not important, since the mean and trend were removed before the data were used. Ship tracks along which the data were obtained are shown in Figures 1 and 6. Profiles of the gravity anomalies and bathymetry projected normal to the local trend of the ridge are shown in Figures 2, 7, 8, and 14. As mentioned above, these profiles have had the mean and trend removed, and also a cosine taper has been applied to the first and last $5 \%$ of each profile. They are not therefore conventional gravity and bathymetry profiles. The mean is given beside each profile, so the original values can be approximately reconstructed.

\section{Method of ANALysis}

It has been recognized for some time that gravity anomalies at sea mainly reflect the effect of sea floor topography and the manner in which it is compensated. Gravity and bathymetry generally correlate closely at short wavelengths (less than a few tens of kilometers) and poorly at longer wavelengths (greater 


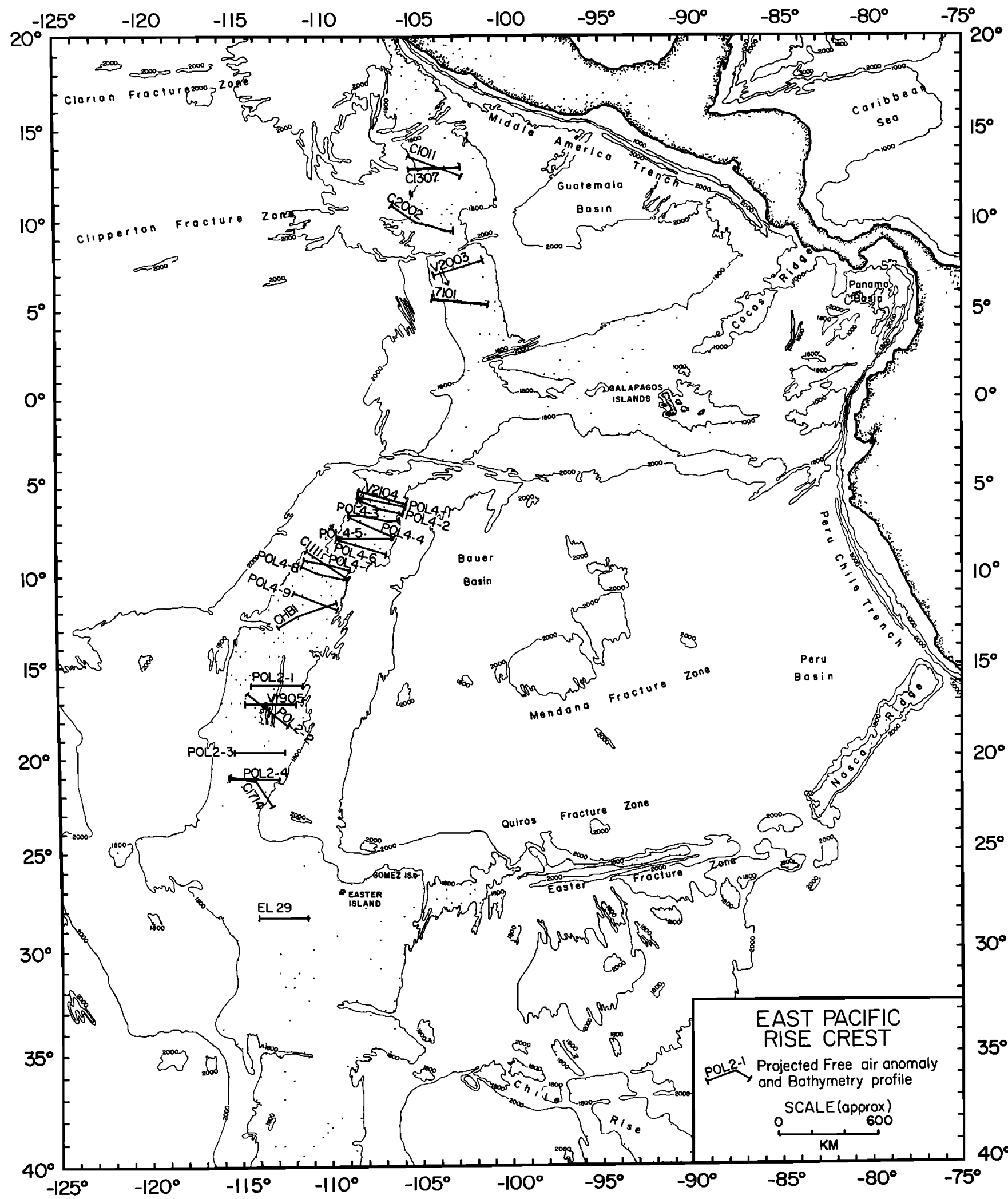

Fig. 1. Location chart for 24 gravity and bathymetry profiles across the East Pacific R ise crest. Each profile is $300 \mathrm{~km}$ long and was projected perpendicular to the ridge crest.

than a few hundreds of kilometers). The change is due to isostatic compensation. Thus in the absence of noise and other effects such as changes in the mean depth of the water, the relationship between gravity and topography as a function of wavelength provides information on isostatic compensation.
We require a transfer function or filter which, when applied to an observed bathymetry profile, converts it to a series which resembles the observed gravity anomaly profile. We obtain this filter using the cross-spectral techniques described in paper 1 [Watts, 1978]. The method used in these studies has the advan- 
EAST PACIFIC RISE CREST
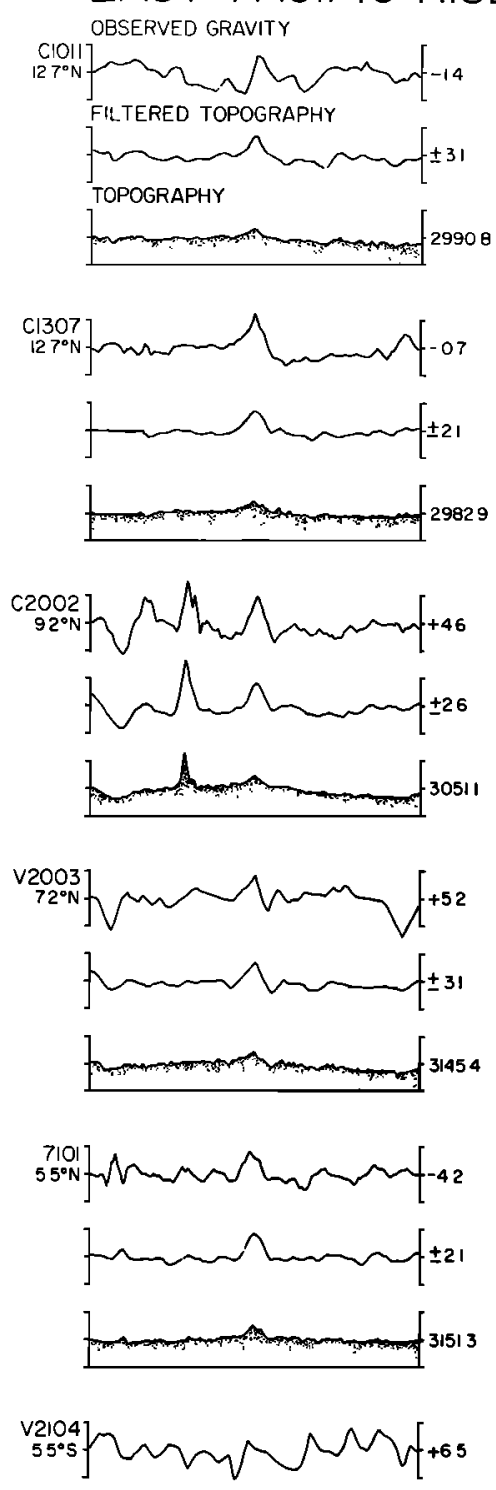

Hman $[ \pm 37$
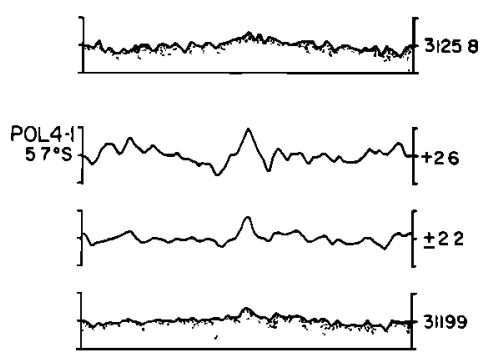

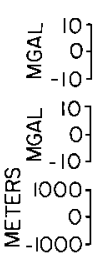

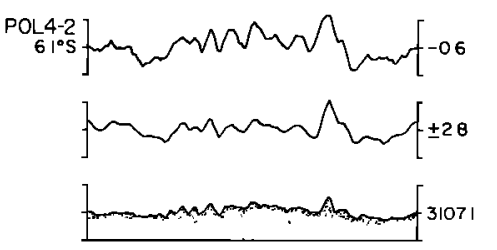

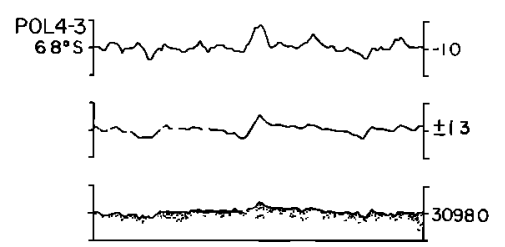

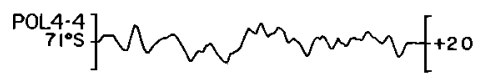

hum $n$ mat20

3164

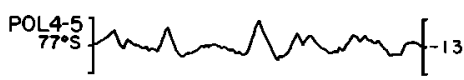

HEm

31032

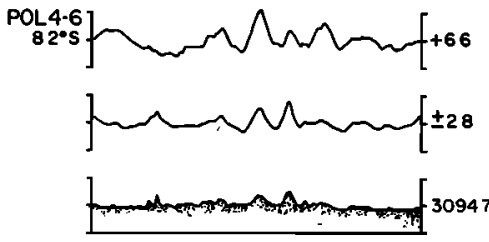

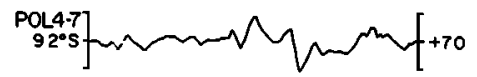

tum

3000

POL2-1] Harm

trum

30513

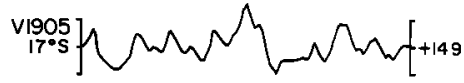
himm $h_{t \pm 36}$

29834

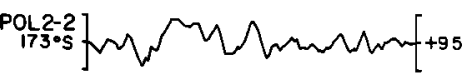

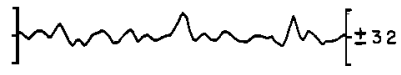

29983

POL2.3

It29

I 31129

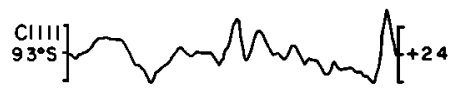

un hment:23

29589

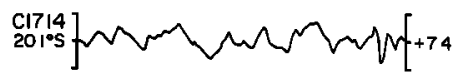

Hnน n

3067

(1964)

$114^{\circ}$ ]

hum Natt27

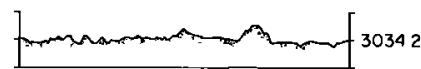

POL2-4

hนm

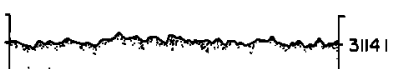

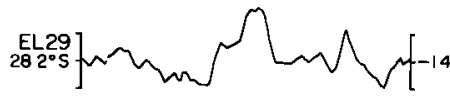

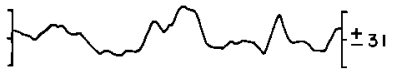

29132

$\underbrace{0}_{K M} 100$

Fig. 2. Observed gravity anomaly, filtered topography, and topography profiles across the East Pacific Rise. The mean and trend have been removed from the observed gravity and bathymetry profiles. The mean is given to the right of each profile. The 'filtered topography' profiles are estimates of the gravity field produced by convolving the filter shown in Figure 4 with the topography profiles. The rms difference between the observed gravity and the filtered topography profiles is given to the right of the filtered topography profile. The location of the profiles is shown in Figure 1. 
tage that the filter and complex admittance (Fourier transform of the filter) is obtained from many relatively short profiles centered on the ridge crest rather than by subdividing a few long profiles. Thus we are assured that the resulting filter is directly applicable to the ridge crest and is not an average filter influenced by data which cross a number of geologic features.

The result of the computations is a filter which, from bathymetric data, reproduces the observed free air gravity anomaly over the region or feature which is being examined. This filter is based completely on the observed relationship between gravity and bathymetry and is not tied to any isostatic model. However, as pointed out by McKenzie and Bowin [1976], the observed filter or complex admittance can be easily compared with isostatic models based on different hypotheses for the manner in which sea floor topography is supported.

\section{Isostasy At Midocean Ridge Crests}

In this section we will use the cross-spectral techniques to investigate the isostatic mechanism at midocean ridge crests. We will concentrate on two ridges in this study. These are the fast spreading East Pacific Rise, which is characterized by smooth topography and an axial horst, and the slow spreading Mid-Atlantic Ridge, which is characterized by rough topography and an axial 'rift valley.' We will thus be able to examine what features are characteristic of ridge crests in general and in what manner the differing tectonic and morphologic natures of the two ridges are expressed.

East Pacific Rise. The data for the East Pacific Rise consist of 24 free air gravity anomaly and bathymetry profiles across the ridge crest. Profiles between latitudes $13^{\circ} \mathrm{N}$ and $28^{\circ} \mathrm{S}$ were included, with a majority of them concentrated between $6^{\circ} \mathrm{S}$ and $21^{\circ} \mathrm{S}$ (Figure 1). Profiles near the Pacific/Nazca/Cocos triple junction were excluded. Each profile was projected normal to the local trend of the ridge and extends $150 \mathrm{~km}$ on either side of the ridge axis. The half spreading rates for this portion of the East Pacific Rise vary from 5 to $8 \mathrm{~cm} / \mathrm{yr}$ [Larson and Chase, 1972; Herron, 1972; Handschumacher, 1976], and the data are thus from regions less than about 3 m.y. old.

The gravity and bathymetry profiles of the rise crest are presented in Figure 2. The ridge crest in these profiles is characterized by a positive horstlike topographic feature about $20 \mathrm{~km}$ across and a few hundred meters high. The characteristic gravity anomaly associated with the central high is a relatively small amplitude (15-25 mGal) high which is 20-30 $\mathrm{km}$ wide and is flanked by smaller-amplitude gravity lows. The bathymetry away from the ridge crest is generally smooth, and in many cases the central high is the largest feature in both the bathymetry and gravity profiles.

The gravity and bathymetric data from each profile were used to obtain 24 independent estimates of the cross spectrum and of the power spectrum of the bathymetry. The resulting averaged spectra were used to calculate the complex admittance $Z\left(k_{n}\right)$, the coherence $\gamma^{2}\left(k_{n}\right)$, and the phase of the admittance $\phi\left(k_{n}\right)$. (See McKenzie and Bowin [1976] or Watts [1978] for the definition of these quantities.) These parameters are plotted as a function of wave number in Figure 3. The smoothness of the $\log _{10}$ admittance curve for wavelengths of greater than about $15 \mathrm{~km}$ is evidence that the same signal was present in the various profiles and that the averaging procedure successfully reduces noise. The phase is near zero for the same range of wavelengths, implying that the admittance is real, as it should be for the earth; and the coherence is high between wavelengths of 15 and $150 \mathrm{~km}$. The coherence is a measure of that portion of changes in the gravity field which can be directly attributed to changes in water depth.
The space domain representation of the complex admittance is the filter shown in Figure 4, which was obtained by an inverse Fourier transform of the admittance. The filter can be thought of as an impulse response function (or $G$ reen's function) which represents the gravity effect of a unit line load on the earth's surface. The negative wings of the filter therefore represent the effects of isostatic compensation.

The degree to which the filter shown in Figure 4 can reproduce the observed free air gravity anomalies can be seen in Figure 2. The filtered topography profiles in Figure 2 were obtained by convolving the East Pacific Rise filter (Figure 4) with the observed bathymetry. The predicted and observed gravity anomalies generally compare well. The rms difference between observed and predicted anomalies does not exceed $\pm 3.7 \mathrm{mGal}$ on any of the profiles and is less than $\pm 3.0 \mathrm{mGal}$ for $66 \%$ of them.

The simplest model to explain the observed admittance is to assume that the gravity anomalies are due only to the sea floor topography and that the topography is uncompensated. The admittance expressing the relationship of gravity to uncompensated topography is given [Walcott, 1976; McKenzie and Bowin, 1976] by

$$
Z\left(k_{n}\right)=2 \pi G\left(\rho_{2}-1.03\right) e^{-k_{n} d}
$$

where $\rho_{2}$ is the density of the topographic relief and $d$ is the mean water depth. This expression is the first term of the series used by Parker [1972] to determine the gravity effect of a twodimensional body and constitutes an approximation of the topography as a density layer at a depth $d$ beneath the surface.
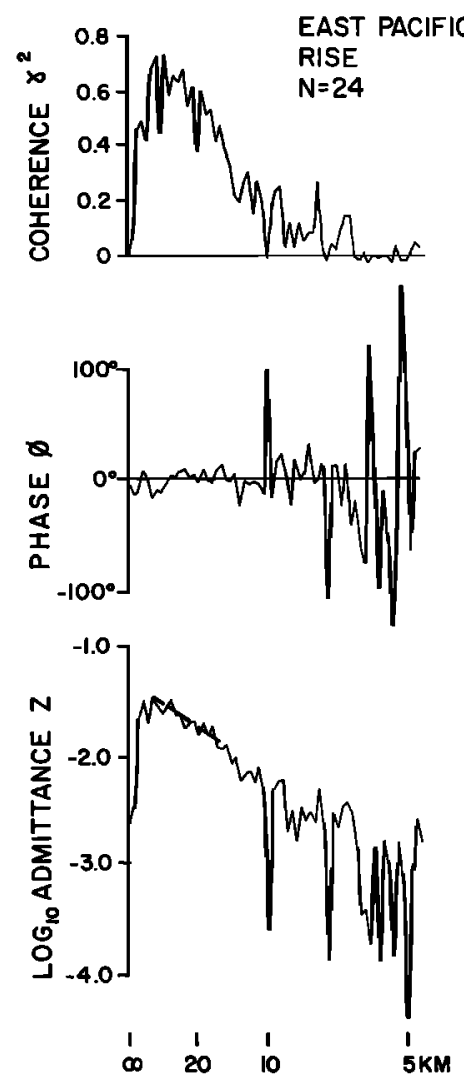

Fig. 3. The coherence, phase (in degrees), and $\log _{10}$ of the amplitude of the admittance determined from the gravity and bathymetry profiles shown in Figure 2 . The dashed line on the $\log _{10}$ admittance curve is a straight line fit to the curve for wavelengths of $32>\lambda>13$ $\mathrm{km}$ and gives an estimate of the mean water depth and density of the topographic relief of $3.219 \mathrm{~km}$ and $2.3 \mathrm{~g} / \mathrm{cm}^{3}$, respectively. The actual mean depth is $3.097 \mathrm{~km}$. 


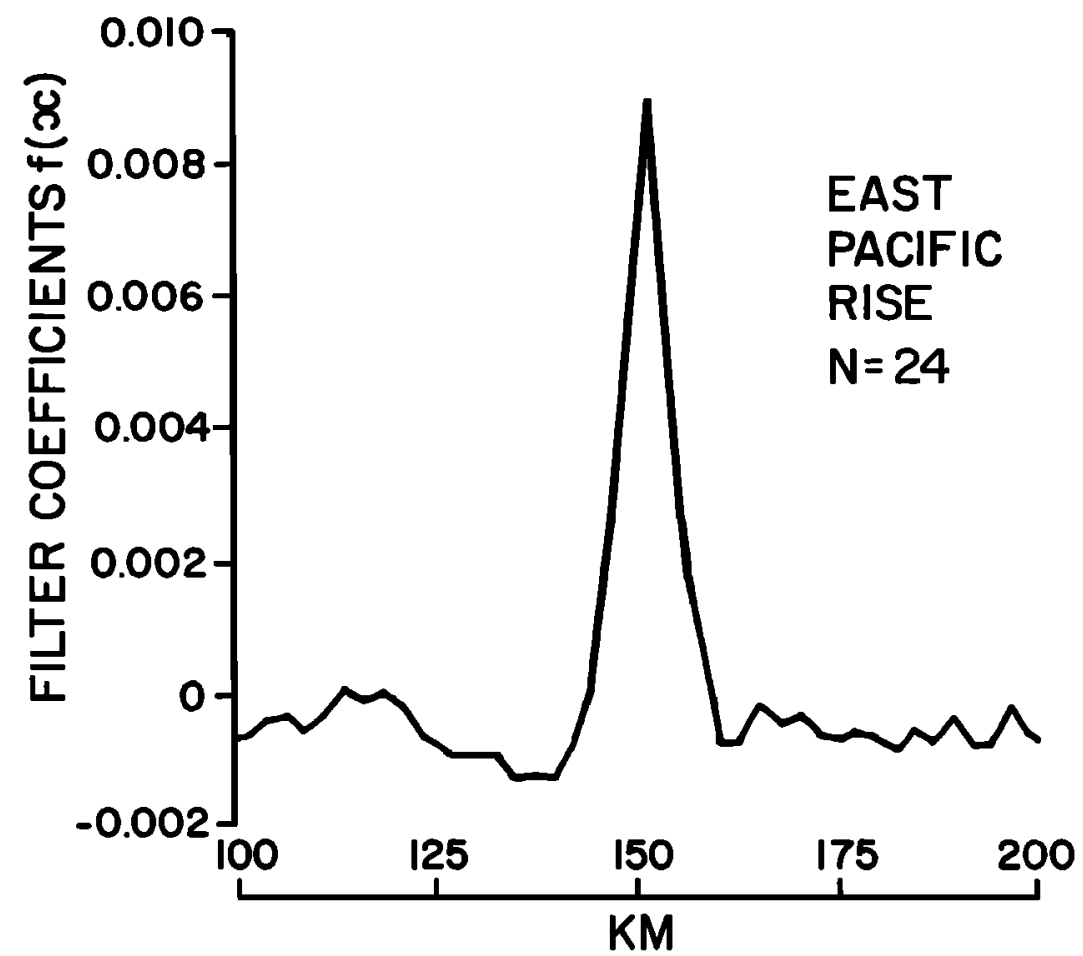

Fig. 4. The filter determined from the gravity anomaly and bathymetry profiles over the East Pacific Rise. When convolved with the bathymetric profiles, this filter produces the 'filtered topography' profiles in Figure 2. The filter is the inverse Fourier transform of the observed admittance values shown in Figures 3 and 5.

Equation (1) gives a straight line on a log admittance plot, and thus an estimate of $\rho_{2}$ and of $d$ can be made by fitting a straight line to values of $\log _{10} Z$ [McKenzie and Bowin, 1976]. A straight line fit to the observed admittance for a wavelength range of $32>\lambda>13 \mathrm{~km}$ gave estimates of $d=3.219 \mathrm{~km}$ and $\rho_{2}$ $=2.33 \mathrm{~g} / \mathrm{cm}^{3}$. The estimated mean water depth, although slightly greater than the observed mean depth, is within the range of observed values. The mean density estimate, however, is somewhat lower than densities usually assumed for oceanic layer 2 . One explanation is that the density appropriate to the topographic relief is that of layer $2 \mathrm{~A}$ rather than of layer 2. Houtz and Ewing [1976] have documented a 1- to 1.5-km-thick layer in crestal regions of midocean ridges with $P$ wave velocities of $3.1-3.3 \mathrm{~km} / \mathrm{s}$. These velocities correspond to densities of approximately $2.3 \mathrm{~g} / \mathrm{cm}^{3}$ using the Nafe-Drake curves.

Although the short-wavelength portion of the $\log _{10} Z$ curve can be fit by a straight line, the admittance decreases rapidly at longer wavelengths because of the effects of isostasy. As a compensated topographic feature becomes wider, the gravity anomalies over its center decrease, and the patterns of gravity and bathymetry become less similar. The nature of the relationship between gravity and bathymetry for various theoretical isostatic models can be determined [Walcott, 1976; McKenzie and Bowin, 1976] and compared to observed values.

The admittance for the Airy model of compensation is given by the sum of two density layers, one at the mean water depth, representing the topography, and one at the depth of compensation, representing the compensation [McKenzie and Bowin, 1976]. The resulting expression is

$$
Z\left(k_{n}\right)=2 \pi G\left(\rho_{2}-1.03\right) e^{-k_{n} d}\left(1-e^{-k_{n} t}\right)
$$

where $t$ is the distance below the sea floor at which compensation is assumed to occur. For simple Airy isostasy, $t$ would normally be the average crustal thickness. The other parameters are as in (1).
A similar procedure is used to determine an expression for the admittance when a plate model of compensation is assumed, although the computations are more involved, since the deflection due to the load must be calculated as part of the computation of the gravity effect of the compensation. McKenzie and Bowin [1976] outline a procedure for the derivation. The expression which we use for the admittance, $Z\left(k_{n}\right)$, differs slightly from that given by McKenzie and Bowin [1976]. The expression which they use (their equation A 16) assumes that the entire crust has the same density as the topographic relief. For the low densities which we have deduced for the topography at the East Pacific Rise, this would result in a density contrast of greater than $1 \mathrm{~g} / \mathrm{cm}^{3}$ at the base of the crust, which is unrealistically high. We have therefore introduced another density contrast within the crust. The resulting admittance is then

$$
\begin{aligned}
& Z\left(k_{n}\right)=2 \pi G\left(\rho_{2}-1.03\right) e^{-k_{n} d}\left\{1-\left[e^{-k_{n} t_{2}}\left(\rho_{\mathrm{g}}-\rho_{2}\right)\right.\right. \\
& \left.\left.+e^{-k_{n} t} \cdot\left(\rho_{m}-\rho_{\mathrm{g}}\right)\right] /\left[\left(\rho_{m}-\rho_{2}\right)+4\left(\rho_{m}-1.03\right) M k^{\prime 2} A B^{-1}\right]\right\}
\end{aligned}
$$

where $t_{2}$ is the thickness of layer $2 ; t_{c}$ is the mean thickness of the crust; $\rho_{\mathrm{g}}$ is the density of layer 3 , taken to be $2.9 \mathrm{~g} / \mathrm{cm}^{3} ; \rho_{m}$ is the density of the upper mantle, taken to be $3.4 \mathrm{~g} / \mathrm{cm}^{3} ; M=$ $E / 3 g h\left(\rho_{m}-1.03\right)$, where $E$ is Young's modulus and the plate thickness is $2 h ; k^{\prime}=k h ; A=\left[\left(\sinh 2 k^{\prime}\right) / 2 k^{\prime}\right]^{2}-1$; and $B=$ $\left[\left(\sinh 4 k^{\prime}\right) / 4 k^{\prime}\right]+1$. (We note that there should be a 2 in the denominator of the constants at the beginning of the expression for $Z$ given by McKenzie and Bowin [1976, equation A 16].)

Calculated admittance curves for the Airy model and the plate model of compensation are superimposed on the observed admittance values from the East Pacific Rise in Figure 5 . The vertical lines through the observed points are the standard errors of the admittance estimates calculated following 
Munk and Cartwright [1966]. At short wavelengths, both sets of calculated curves asymptotically approach the straight line representing uncompensated topography. The difference between the two schemes of compensation appears mainly at long wavelengths.

The calculated admittance curves for the Airy model show that an average crustal thickness of $10-20 \mathrm{~km}$ is required to explain the oberved admittance. When the admittance values for wave numbers of $0-0.45(\lambda>14 \mathrm{~km})$ are considered, the best fitting crustal thickness in a least squares sense is $13 \mathrm{~km}$. This value is significantly greater than the crustal thickness of $5-6 \mathrm{~km}$ determined from seismic refraction measurements in the region [Shor et al., 1970; Rosendahl et al., 1976]. The crustal parameters deduced for an Airy model of local isostatic compensation thus do not agree well with direct measurements in the vicinity.

The plate model of regional compensation results in calculated admittance values which adequately explain the observed admittance and show that an elastic plate thickness in the range of $2-6 \mathrm{~km}$ is required. The best fitting effective elastic plate thickness in a least squares sense for wave numbers from
0 to 0.45 is $6 \mathrm{~km}$. This value is considerably less than the effective elastic thickness of $20-25 \mathrm{~km}$ deduced from loads formed on old oceanic lithosphere [Walcott, 1970; Watts et al., 1975; Watts, 1978] and is also less than the estimate of $10 \mathrm{~km}$ deduced by McKenzie and Bowin [1976] from topography in the Atlantic Ocean. It can easily be seen from Figure 5 that the elastic plate thickness in the Pacific cannot be as great as 10 $\mathrm{km}$.

We have also determined the admittance for sets of profiles $150 \mathrm{~km}$ and $960 \mathrm{~km}$ long across the East Pacific Rise to determine if there is any change in the elastic plate thickness with crustal age. The best fitting plate thicknesses are $5 \mathrm{~km}$ for the $150-\mathrm{km}$-long profiles and $6 \mathrm{~km}$ for $960-\mathrm{km}$-long profiles.

Analyses of sets of profiles of different lengths therefore, including those confined to the immediate vicinity of the ridge crest and those extending large distances across the ridge flank, give similar values for the admittance over the East Pacific Rise crest. This supports the hypothesis [e.g., Le Pichon et al., 1973; Needham and Francheteau, 1974] that ridge flank topography is created at or near the ridge axis, frozen in, and subsequently transported from the ridge atop the rapidly
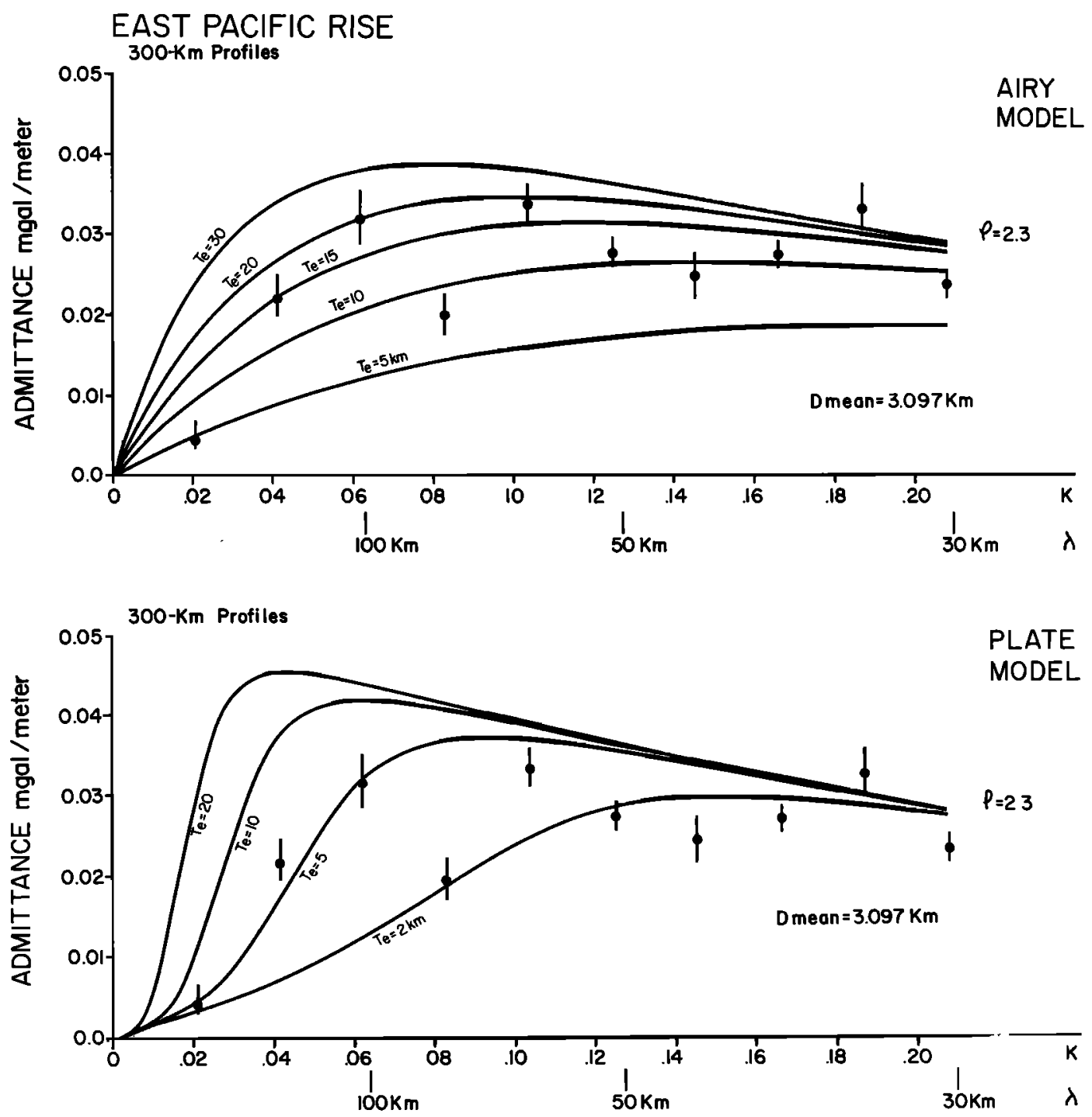

Fig. 5. Observed admittance values (dots) for the East Pacific Rise crest compared with theoretical admittance curves for two isostatic models. The vertical bars extend 1 standard deviation on either side of the value and are calculated by the method of $M$ unk and Cartwright [1966]. An oceanic crustal thickness of 10-20 km is required to fit the observed admittance values using the Airy model. The best fitting elastic thickness for the plate model is $6 \mathrm{~km}$. 


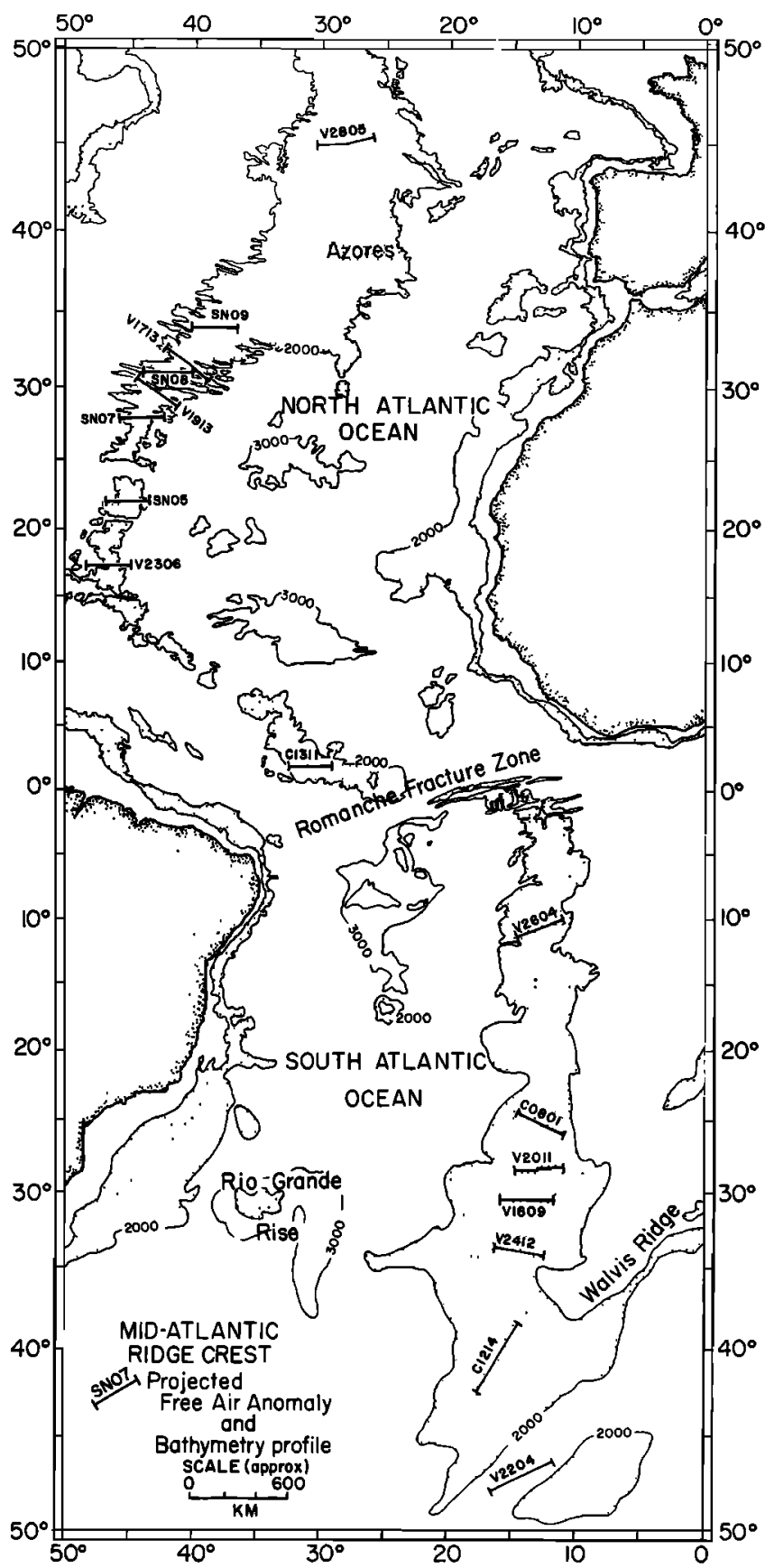

Fig. 6. Location chart for 16 gravity and bathymetric profiles across the Mid-Atlantic Ridge. Each profile is $400 \mathrm{~km}$ long and was projected perpendicular to the ridge crest.

thickening lithosphere. Even though the lithosphere thickens with age, material is added in such a manner that it does not alter the original deformed configuration of the crust giving rise to the gravity anomalies.

Mid-Atlantic Ridge. The data for the Mid-Atlantic Ridge consist of 16 free air gravity anomaly and bathymetry profiles across the ridge crest between $45^{\circ} \mathrm{N}$ and $47^{\circ} \mathrm{S}$. Each profile was projected perpendicular to the ridge and extends $200 \mathrm{~km}$ on either side of the ridge axis. The location of the profiles is shown in Figure 6. Profile V1713 was analyzed in detail by Talwani et al. [1965] and is also discussed by Talwani et al. [1972]. The SN05 profile at $22^{\circ} \mathrm{N}$ is close to the area studied by Van Andel and Bowin [1968]. Since the half spreading rate in the Atlantic varies from about 1.2 to $2 \mathrm{~cm} / \mathrm{yr}$ [Pitman and
Talwani, 1972; Ladd et al., 1975], the profiles extend out to crust of 10-17 m.y. in age.

The gravity and bathymetry profiles in the North Atlantic are presented in Figure 7, and those in the South Atlantic in Figure 8 . The ridge crest is associated with a rift valley in every profile across the $\mathbf{M i d}$-A tlantic $\mathbf{R}$ idge. The rift valley varies in depth from up to $1500 \mathrm{~m}$ in profiles such as V2805 and SN05 in the North Atlantic and V2604 and C0801 in the South Atlantic, where it is quite distinct, to no more than a few hundred meters in profiles such as V1913 in the North Atlantic. It is, however, always associated with a very prominent free air gravity anomaly low and, where they are well developed, with large gravity highs over the rift mountains. The gravity anomalies associated with the rift valley and rift mountains are generally the dominant feature on the free air gravity profiles.

The complex admittance, coherence, and phase of the admittance were calculated from the averaged spectra of the profiles as was done for the East Pacific Rise and are plotted as a function of wave number in Figure 9. As was the case with the East Pacific Rise, the $\log _{10}$ admittance curve is smooth for wavelengths of greater than about $15 \mathrm{~km}$. Also, in this range of wavelengths the phase is near zero, and the coherence is high, indicating that a definite signal is present in the group of profiles. The degree to which the Mid-Atlantic Ridge filter, shown in Figure 10, is capable of reproducing the gravity anomalies can be judged from the 'filtered topography' and 'difference gravity' profiles in Figures 7 and 8.

The observed admittance values with their standard errors are plotted in Figure 11 along with calculated admittance curves for the Airy and plate models of compensation. It can easily be seen that an average crustal thickness of greater than $20 \mathrm{~km}$ is required to explain the relationship between gravity and bathymetry according to the Airy hypothesis. This is several times the observed oceanic crustal thickness. The effective plate thickness and density which best fit the observed admittance in a least squares sense are $9 \mathrm{~km}$ and $2.6 \mathrm{~g} / \mathrm{cm}^{3}$. This value for the elastic plate thickness is nearly the same as the value of $10 \mathrm{~km}$ determined by MCKenzie and Bowin [1976] for the Atlantic. The Atlantic value is somewhat greater than that determined for the East Pacific Rise, and the difference appears to be real and significant. The difference can be easily seen by comparing the filters from the two ridges. Although the mean depth is nearly the same for the two sets of profiles ( $3159 \mathrm{~m}$ for the Atlantic and $3097 \mathrm{~m}$ for the Pacific), the MidAtlantic Ridge filter (Figure 11) has an amplitude nearly $50 \%$ greater than the East Pacific Rise filter (Figure 4). It is also somewhat wider than the East Pacific Rise filter.

\section{TECTONIC IMPLICATIONS}

A result of particular interest is that the effective elastic thickness determined from small-scale topography appears to differ between ridge systems. Low values of the elastic thickness (2-6 km) were determined for the East Pacific R ise crest, while higher values (7-13 km) were determined for the MidAtlantic Ridge. These differences appear to be real and significant.

The difference in the relationship between gravity and bathymetry over the two ridge crests is illustrated in Figure 12, in which the isostatic response function $\phi$ is plotted against wavelength. The response function is obtained by writing the admittance in the form

$$
Z\left(k_{n}\right)=2 \pi G\left(\rho_{2}-1.03\right) e^{-k_{n}^{d} \phi\left(k_{n}\right)}
$$

It thus serves to normalize the admittance for variations in 

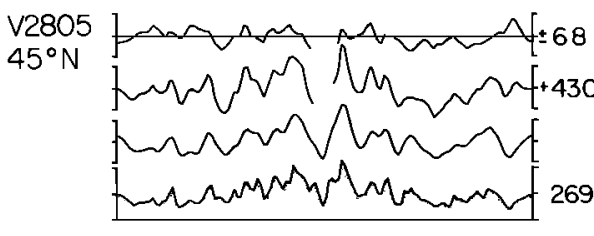

SNO9

$34^{\circ} \mathrm{N}$

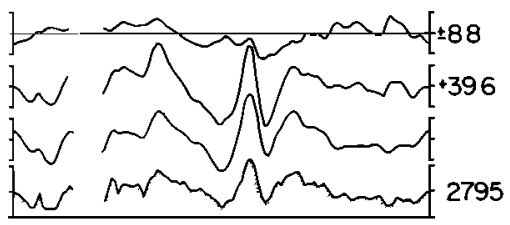

$\mathrm{V} 1713$
$32^{\circ} \mathrm{N}$

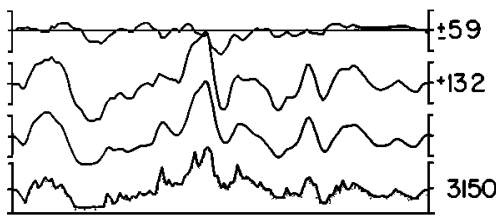

SNO8

$31^{\circ} \mathrm{N}$

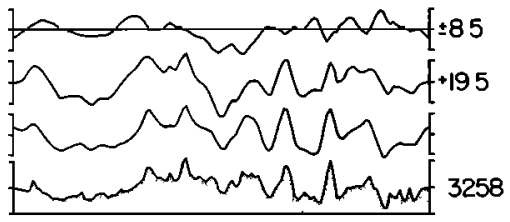

$\mathrm{V} 1913$

$30^{\circ} \mathrm{N}$

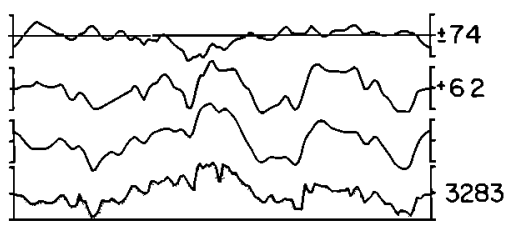

$\mathrm{SNO} 7$ $28^{\circ} \mathrm{N}$ DIFFERENCE GRAVITY OBSERVED GRAVITY FILTERED TOPOGRAPHY TOPOGRAPHY
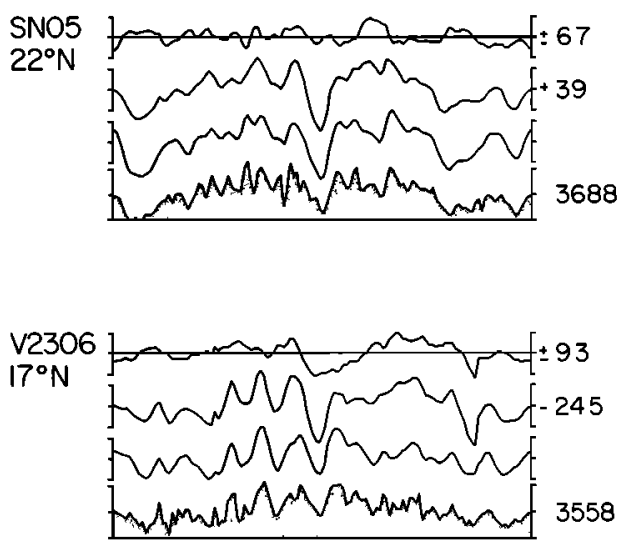

$\mathrm{CI3I}$

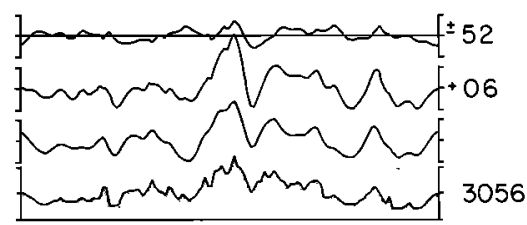

\begin{tabular}{rrr}
\hline 0 & 50 & 100 \\
\hline & KM &
\end{tabular}

Fig. 7. Observed gravity anomaly, topography, and difference gravity anomaly profiles across the Mid-Atlantic Ridge crest in the North Atlantic. The mean and trend are removed from the observed gravity and bathymetry profiles, and the mean is given to the right of each profile. The filtered topography profiles are estimates of the gravity field produced by convolving the filter shown in Figure 10 with the topography profiles. The difference gravity is the difference between the observed gravity and filtered topography. The rms difference is given by each difference gravity profile. Location of profiles is shown in Figure 6.

water depth and topographic density. If $\phi=1$, then $Z\left(k_{n}\right)=$ $2 \pi G\left(\rho_{2}-1.03\right) e^{-k_{n} d}$, which represents the condition that topography is uncompensated. If $\phi=0$, then $Z=0$, implying zero free air gravity anomalies and, for sufficiently large wavelengths, complete compensation. It can be easily seen that while the East Pacific Rise and Mid-Atlantic Ridge values fit the pattern expected for a plate model, the values definitely represent separate curves with different plate thicknesses.

The difference in the relationship between gravity and bathymetry over the two ridge crests is also illustrated in Figure 13, where the Mid-Atlantic Ridge and East Pacific R ise filters are both convolved with profiles across the Mid-Atlantic Ridge. The difference between the resulting gravity anomalies is easily seen, as is the fact that the East Pacific filter does a relatively poor job of reproducing the observed anomalies.

Differences in the elastic plate thickness at ridge crests can be interpreted in terms of differences in the thermal regime beneath the ridge crests. Our data would thus imply relatively higher temperatures under the East Pacific R ise and relatively lower average temperatures under the Mid-Atlantic Ridge crest. Sleep [1975] and Lachenbruch [1973, 1976] have suggested that temperature differences may reflect differences in 


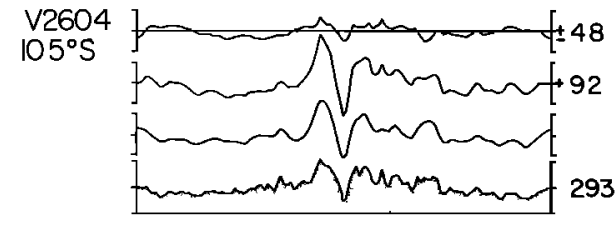

$\mathrm{COBO}$

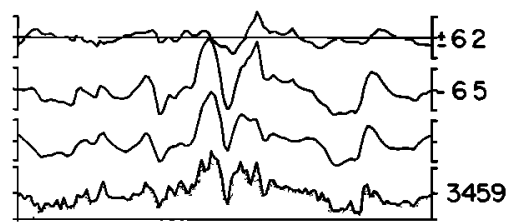

$\mathrm{V} 2 \mathrm{Oll}$

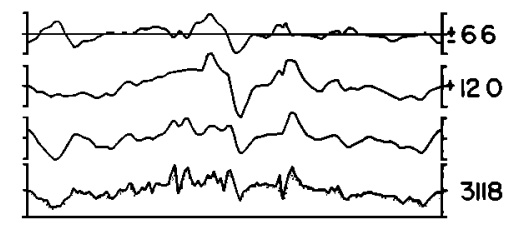

Vi809

$305^{\circ} \mathrm{S}$

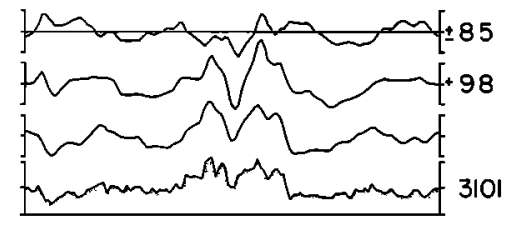

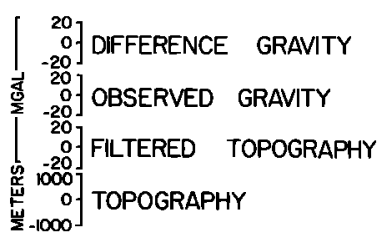
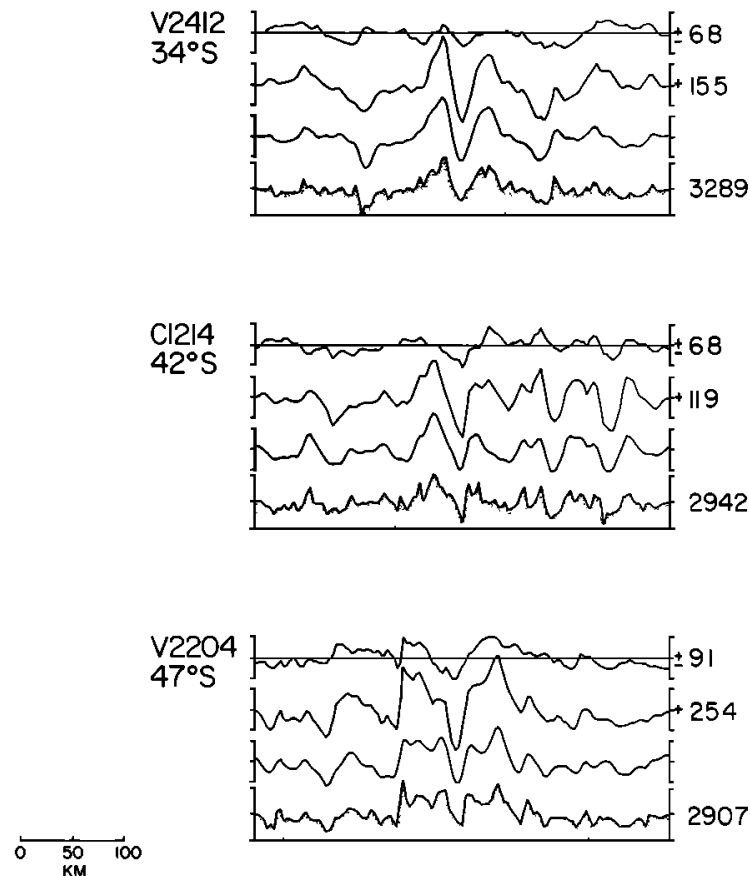

Fig. 8. Observed gravity anomaly, topography, and difference gravity anomaly profiles across the Mid-A tlantic Ridge in the South A tlantic. The mean and trend are removed from the observed gravity and bathymetry profiles, and the mean is given to the right of each profile. The filtered topography profiles are estimates of the gravity field produced by convolving the filter shown in Figure 10 with the topography profiles. The difference gravity is the difference between the observed gravity and filtered topography. The rms difference is given by each difference gravity profile. Location of profiles is shown in Figure. 6.

the geometry of the magma reservoir or conduit for the ascending hot mantle material. High average temperatures would represent relatively wide conduits, and low average temperatures relatively narrow conduits. A number of model studies have been carried out [Sleep, 1969, 1975; Sleep and Rosendahl, 1979; Lachenbruch, 1973, 1976; Cann, 1974] which relate ridge crest topography to the geometry of the magma conduit, viscosity of the magma, and the static pressure difference at the base of the conduit. In these models the style of axial topography is related to the conduit width by considering the effect of viscous dissipation on the sides of the conduit. For wide conduits, viscous forces are small, allowing magma to ascend to an elevation controlled by hydrostatic pressure, thus favoring the formation of an axial horst. For narrow conduits the viscous stresses are larger, retarding the rise of material in the conduit and favoring the creation of an axial valley. In addition, the viscous stresses on the walls of the conduit will act to help support the rift mountains, the maintenance of which implies the presence of quite large stresses.

The relationship of plate thickness and thus temperatures beneath the ridge crest to the style of topography at a ridge crest can be investigated by considering the Reykjanes Ridge, which is the exception to the general observation [Anderson and Noltimier, 1973] that fast spreading ridges are associated with axial blocks and slow spreading ridges with rift valleys. According to the models which we have just discussed, it would be expected that the elastic plate thickness under the Reykjanes Ridge crest would be quite small.

Figure 14 shows the results of convolving the East Pacific Rise and Mid-Atlantic Ridge filters corrected for the difference in mean water depth with five profiles across the Reykjanes Ridge crest. It can be seen that the East Pacific $R$ ise filter consistently gives predicted anomalies which are closer to the observed anomalies than does the Mid-Atlantic Ridge filter. In particular, the Mid-Atlantic Ridge filter results in gravity anomalies over the central block which are larger than are observed and does not reproduce the gravity lows on either side of the central block. In fact, on most of the profiles the East Pacific filter does not completely reproduce the amplitude of the lows either, suggesting that the elastic thickness may be slightly less than that at the East Pacific Rise.

The thermal models for the ridge axis topography also have 

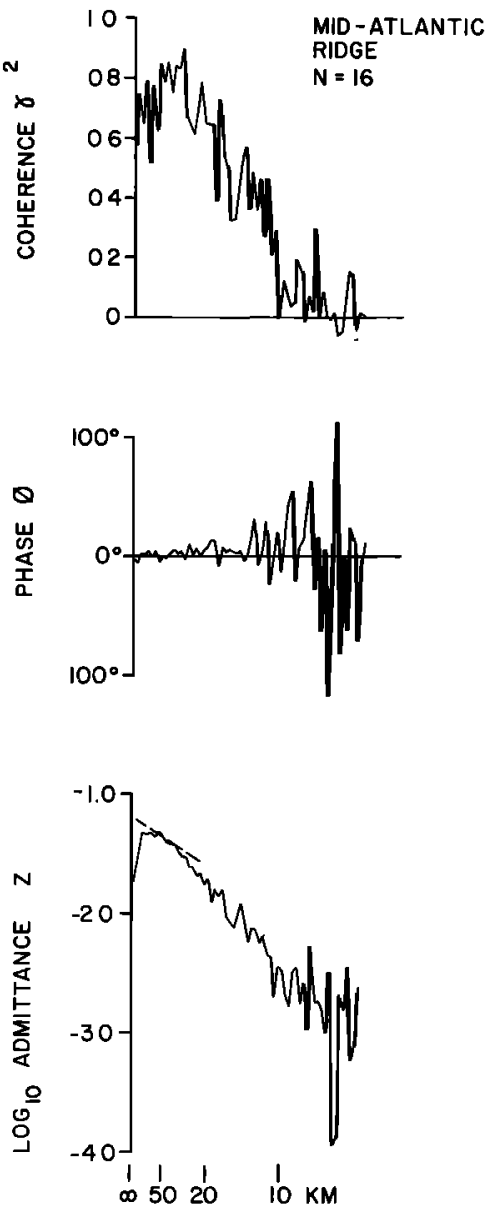

Fig. 9. The coherence, phase (in degrees), and $\log _{10}$ of the amplitude of the admittance determined from the gravity and bathymetry profiles shown in Figures 7 and 8 . The dashed line on the $\log _{10}$ admittance gives the admittance for uncompensated topography with a density of $2.6 \mathrm{~g} / \mathrm{cm}^{3}$ and a water depth of $3.159 \mathrm{~km}$. implications for the state of isostasy at the ridge axis. These models can be tested using the relationship of gravity and bathymetry over ridge crests. Since for wide conduits (or abnormally low viscosities) the ridge crest axial elevation is determined by hydrostatic equilibrium, these models predict that axial blocks should be in a state of isostatic equilibrium. Conversely, at ridges where an axial rift valley is present, the viscous stresses are relatively large, and the ridge axis is depressed to a level below that of hydrostatic equilibrium. Thus the ridge axis should be associated with a mass deficiency and not be in isostatic equilibrium when a rift valley is present.

The state of isostatic equilibrium at ridge crests can be considered by examination of simple regional isostatic anomalies which assume the plate model of compensation. Bouguer and regional isostatic anomaly profiles across the Reykjanes Ridge and the Mid-Atlantic Ridge are shown in Figure 15. Although both profiles show a Bouguer anomaly low centered at the ridge crest, there is a difference in the character of the lows. The Bouguer anomaly low over the Reykjanes Ridge is smooth, gentle, and at least $100 \mathrm{~km}$ wide. This low is the central portion of the broad Bouguer anomaly low which expresses compensation of the entire ridge and is eliminated in the regional isostatic anomaly. In contrast, the Bouguer anomaly low, over the Mid-Atlantic Ridge is bounded by steep gradients, is confined to the inner portion of the rift valley, and is not removed in the regional isostatic anomaly. The presence of a gravity low in both Bouguer and isostatic anomaly profiles implies that not only is the rift valley uncompensated but that in addition, a subsurface mass deficiency is associated with it.

Several investigators [e.g., Anderson and Noltimier, 1973] have suggested that the type of axial topography is spreading rate dependent, with axial horsts characterizing fast spreading ridges and rift valleys slow spreading ridges. We prefer, however, to consider the axial topography to be thermally controlled and thus to be primarily a function of the plate thickness. This is demonstrated at the Reykjanes Ridge, where a

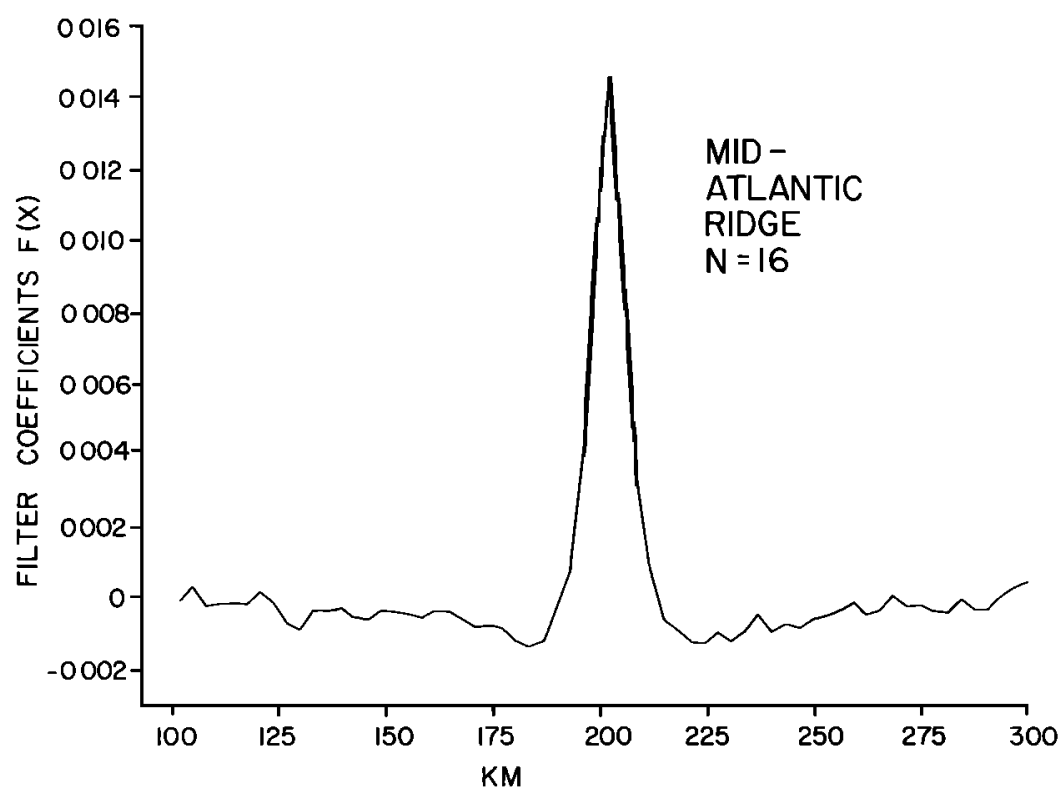

Fig. 10. The filter determined from the gravity anomaly and bathymetry profiles over the Mid-A tlantic Ridge shown in Figures 7 and 8. When convolved with the bathymetric profiles, this filter produces the 'filtered topography' profiles in Figures 7 and 8. The filter is the inverse Fourier transform of the observed admittance values shown in Figures 9 and 11 . 

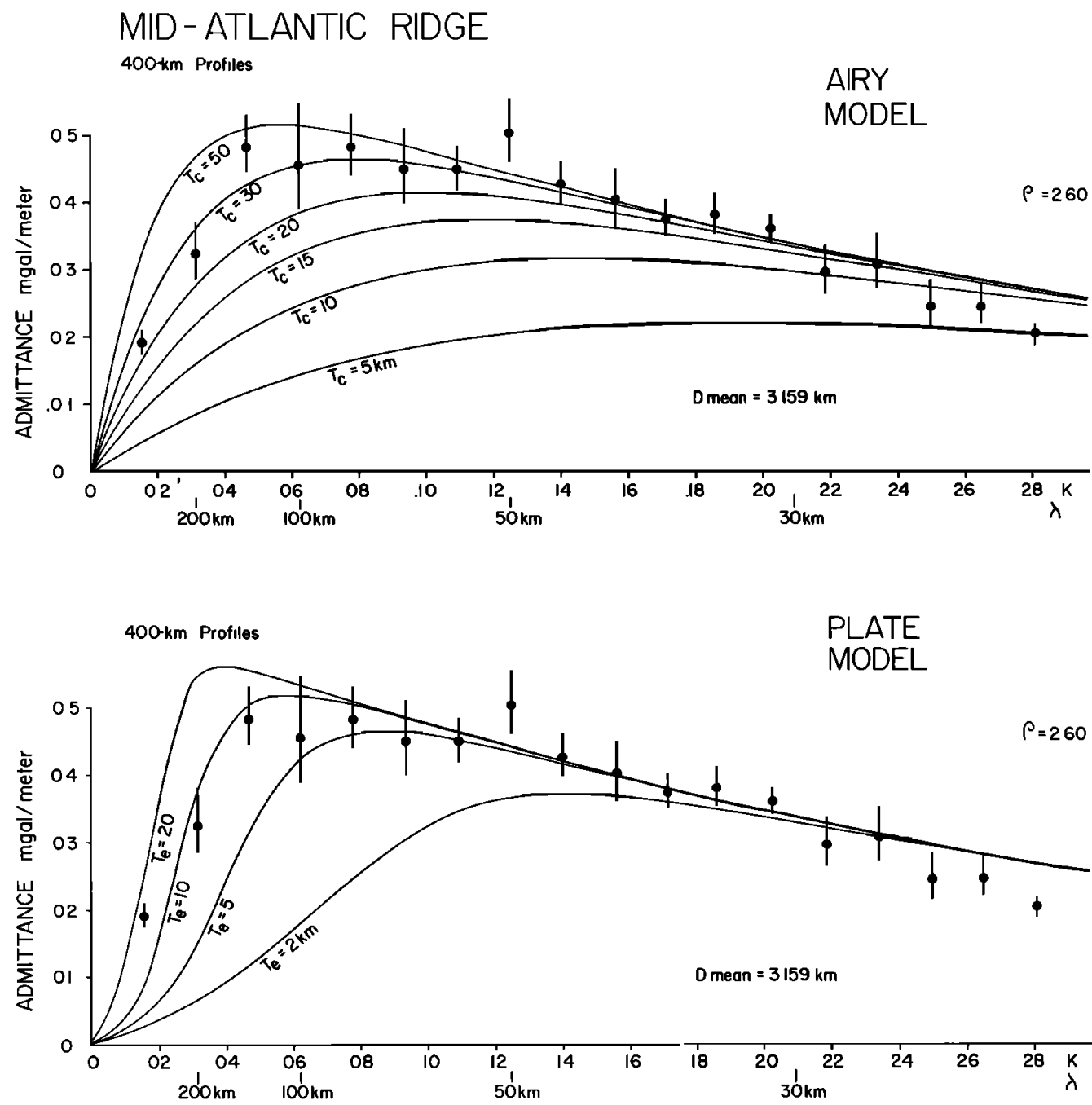

Fig. 11. Observed admittance values (dots) for the Mid-Atlantic Ridge crest compared with theoretical admittance curves for two isostatic models. The vertical bars extend 1 standard deviation on either side of the value and are calculated by the method of Munk and Cartwright [1966]. An oceanic crustal thickness of greater than $20 \mathrm{~km}$ is required to fit the observed admittance values using the Airy model. The best fitting effective elastic thickness for the plate model is $9 \mathrm{~km}$.

slow spreading ridge is characterized by an axial horst. This ridge probably has the smallest elastic plate thickness of any of the ridges considered in this study.

The average temperature in the vicinity of the ridge crest is, however, dependent on the spreading rate. The depth to an isotherm is a function of age [Sclater and Francheteau, 1970], so as the spreading rate increases, isotherms migrate outward, resulting in higher average temperatures beneath the immediate vicinity of the ridge crest.

Turcotte [1974] gives an expression for the temperature as a function of depth and of distance from the ridge crest in a form which is suitable for use near the ridge axis. His expression for the temperature $T_{z}$ at a depth $Z$ near or at the ridge axis is

$$
\frac{T_{z}-T_{s}}{T_{L}-T_{s}}=\operatorname{erf}\left\{\frac{Z}{2}\left[\frac{u}{x_{0} k}\right]^{1 / 2}\right\}
$$

where $T_{s}$ is the surface temperature, $T_{L}$ is the temperature of the solidus, $u$ is the spreading rate, $k$ is the thermal diffusivity, and $x_{0}$ is a parameter which describes the thermal structure of the ridge crest. The expression is calibrated through the parameter $x_{0}$, which has dimensions of distance. Although the elastic thickness is probably both temperature and pressure dependent, we will assume, following the results of Watts [1978], that the $450^{\circ} \mathrm{C}$ isotherm defines the elastic thickness. With $T_{s}=0, T_{L}=1325^{\circ} \mathrm{C}, T_{z}=450^{\circ} \mathrm{C}, Z=T_{e}=9 \mathrm{~km}$ (value obtained for the Mid-Atlantic Ridge), $u=1.5 \mathrm{~cm} / \mathrm{yr}$, and $k=$ $0.007 \mathrm{~cm}^{2} / \mathrm{s}$ we obtain $x_{0}=132 \mathrm{~km}$. Substituting $x_{0}=132 \mathrm{~km}$ in (5) results in a curve relating $T_{e}$ and $u$. This curve is plotted in Figure 16.

The East Pacific Ridge crest falls close to the theoretical curve, which is constrained to pass through the Mid-Atlantic Ridge value. Thus the observed differences in the elastic thickness between the Mid-Atlantic R idge and East Pacific R ise can be explained by a simple spreading rate dependent thermal model for the accreting plate boundary.

It is apparent, however, that differences in spreading rate cannot explain the values of elastic thickness determined for the Reykjanes Ridge crest. The Reykjanes Ridge has a spreading rate of about $1 \mathrm{~cm} / \mathrm{yr}$, which corresponds to a predicted value for the elastic thickness of about $11 \mathrm{~km}$ (Figure 16). We have previously concluded that it is not possible to explain the observed gravity anomalies over the Reykjanes Ridge for an 


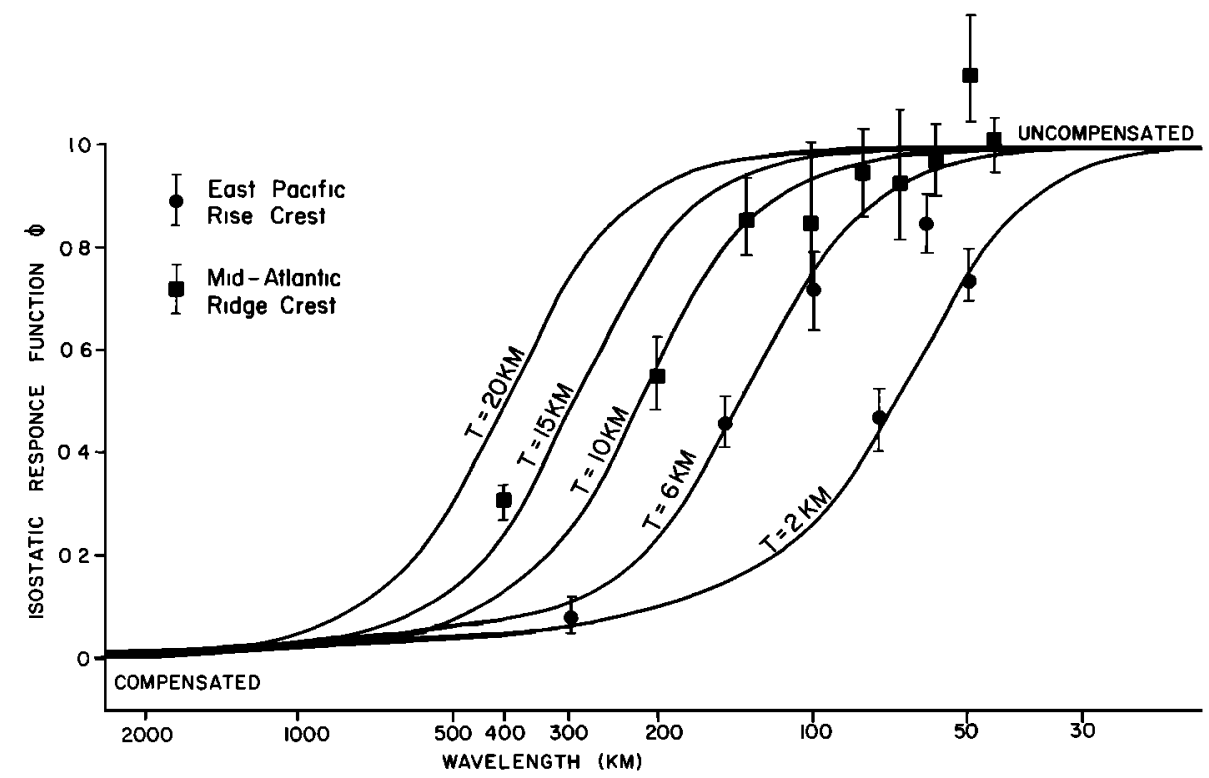

Fig. 12. Plot of the isostatic response function $\phi$ as a function of wavelength on a log plot for the East Pacific Rise crest and Mid-A tlantic Ridge. The various curves represent expected response functions for various thickness elastic plates. The isostatic response function normalizes the admittance for differences in water depth and density.

elastic thickness greater than about $6 \mathrm{~km}$. The differences between the Reykjanes Ridge crest value and the predicted curve which fits the East Pacific Rise and Mid-Atlantic Ridge can be explained if the thermal structure of the Reykjanes $\mathrm{R}$ idge crest differs significantly from the other ridge crests. In order to explain these differences, temperatures would be required to be anomalously high beneath the R eykjanes $\mathrm{R}$ idge.

The presence of unusually high temperatures beneath the Reykjanes Ridge has been suggested by several investigators. Schilling [1973] explained anomalously shallow topography

\section{NORTH ATLANTIC}

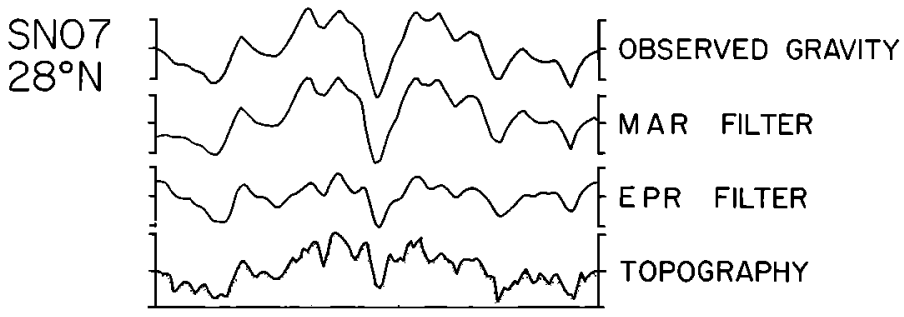

\section{SOUTH ATLANTIC}

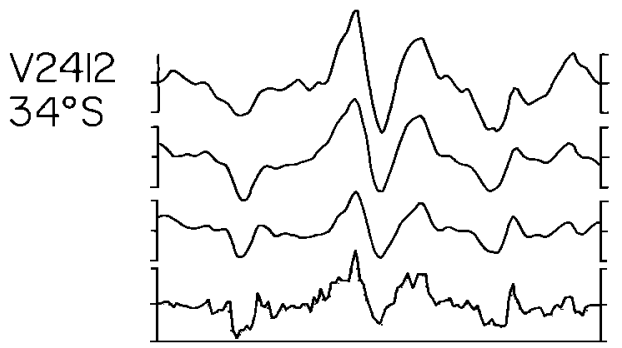

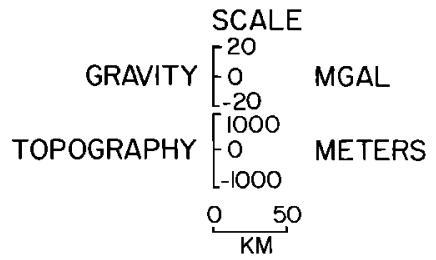

Fig. 13. Representative topography profiles from the North A tlantic and South A tlantic were convolved with the filters determined from the East Pacific R ise and the Mid-A tlantic Ridge to produce the curves labelled E.P.R. filter and M.A.R. filter. The observed gravity is shown at the top of each set of profiles. The difference in the relationship of gravity to bathymetry is shown by the fact that while the M.A.R. filter fits the data well, the E.P.R. filter produces anomalies which are much too small. 
REYKJANES RIDGE

MID -ATLANTIC RIDGE FILTER
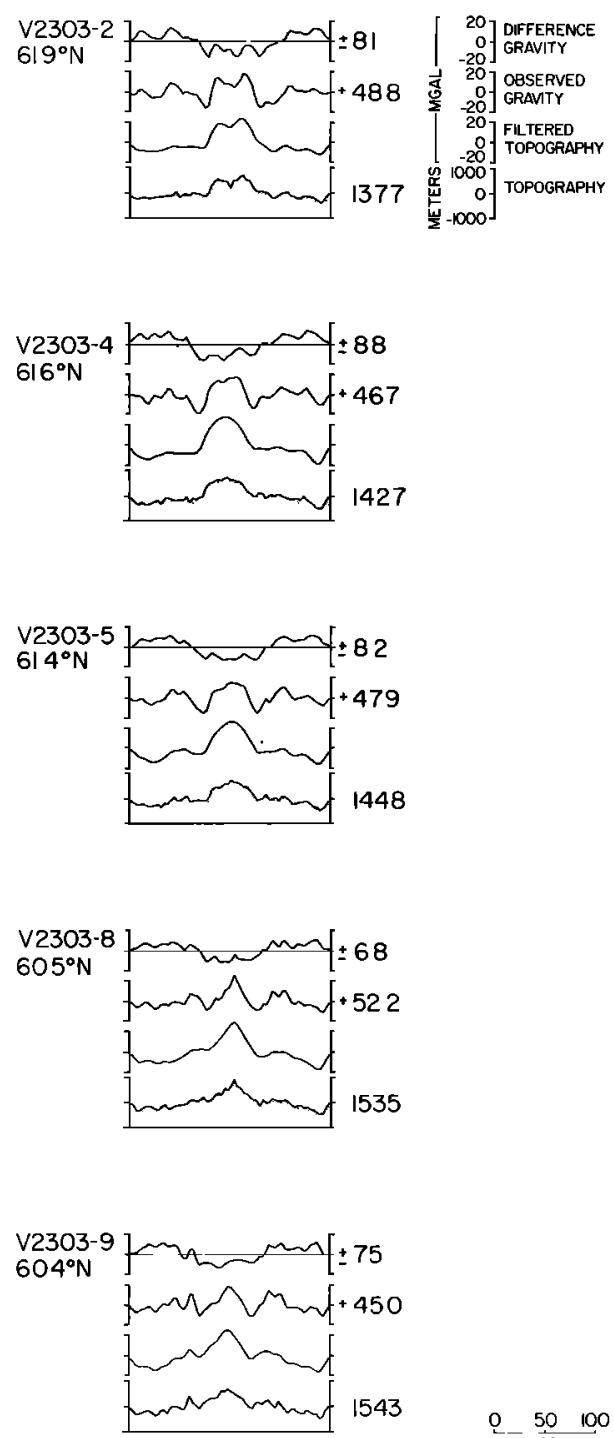

EAST PACIFIC RISE FILTER
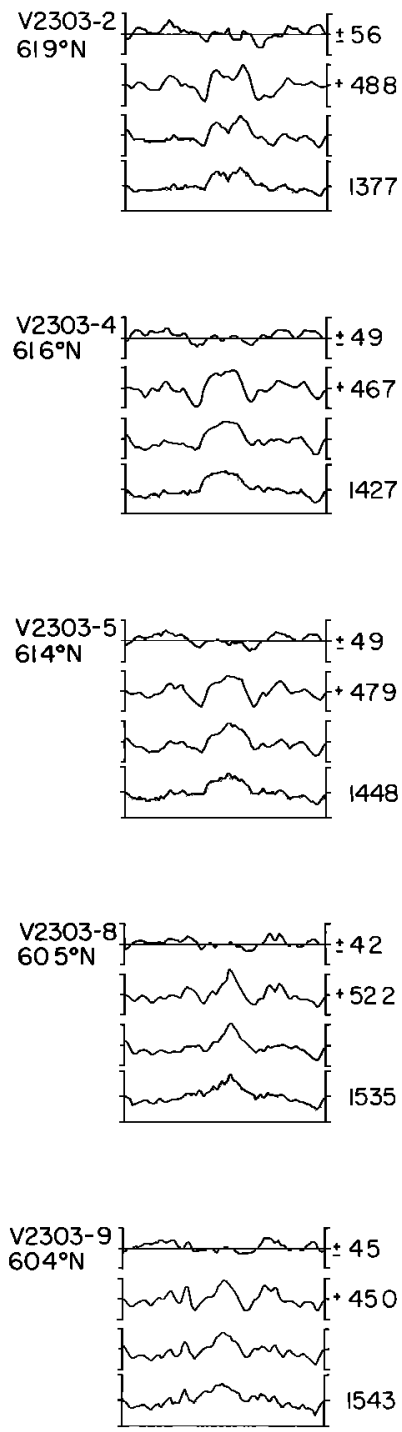

Fig. 14. Comparison of observed free air gravity anomalies with the anomalies produced by convolving the East Pacific Rise and Mid-A tlantic Ridge filters with five topographic profiles across the Reykjanes Ridge. The observed gravity and topography profiles are discussed by Talwani et al. [1971], and the numbering system for the profiles corresponds to that used in their paper. The mean water depth and free air anomaly for each profile are given next to the observed profiles, and the rms difference between the observed and calculated gravity anomalies is given by each difference gravity profile.

and geochemical anomalies on the Reykjanes Ridge in terms of a narrow mantle plume situated beneath Iceland. Vogt [1974] has constructed a model for the evolution of the northern North Atlantic based on the hypothesis of a narrow mantle plume beneath Iceland through which hot mantle material is brought to the surface and then flows away from Iceland beneath the ridge crests. Recently, Talwani and Eldholm [1977] and Cochran and Talwani [1977] have argued in favor of a hot spot in the upper mantle which is much larger than the island of Iceland. In either case there is compelling geophysical and geochemical evidence for anomalously high temperatures beneath the Reykjanes Ridge crest.

These results therefore suggest that differences in spreading rate may explain the differences in elastic thickness (and thus of the style of axial topography) between most 'normal' ridge crests. However, in regions of anomalous depth such as the
Reykjanes Ridge, processes other than variations in thermal structure due to different spreading rates appear to operate. There is good evidence that these are related to anomalous thermal processes immediately beneath the ridge crest.

\section{SUMMARY AND CONCLUSIONS}

We have examined the relationship between gravity and bathymetry over midocean ridge crests by using cross-spectral filtering techniques. The following conclusions may be drawn from this study.

1. The most satisfactory model for the compensation of sea floor topography near the ridge crest is the regional isostatic or elastic plate model. The effective elastic plate thicknesses are 2-6 km over the East Pacific Rise and Reykjanes Ridge to $7-13 \mathrm{~km}$ over the Mid-Atlantic Ridge.

2 . These estimates for the elastic thickness are significantly 


\section{REYKJANES RIDGE CREST $\left(61.4^{\circ} \mathrm{N}\right)$}

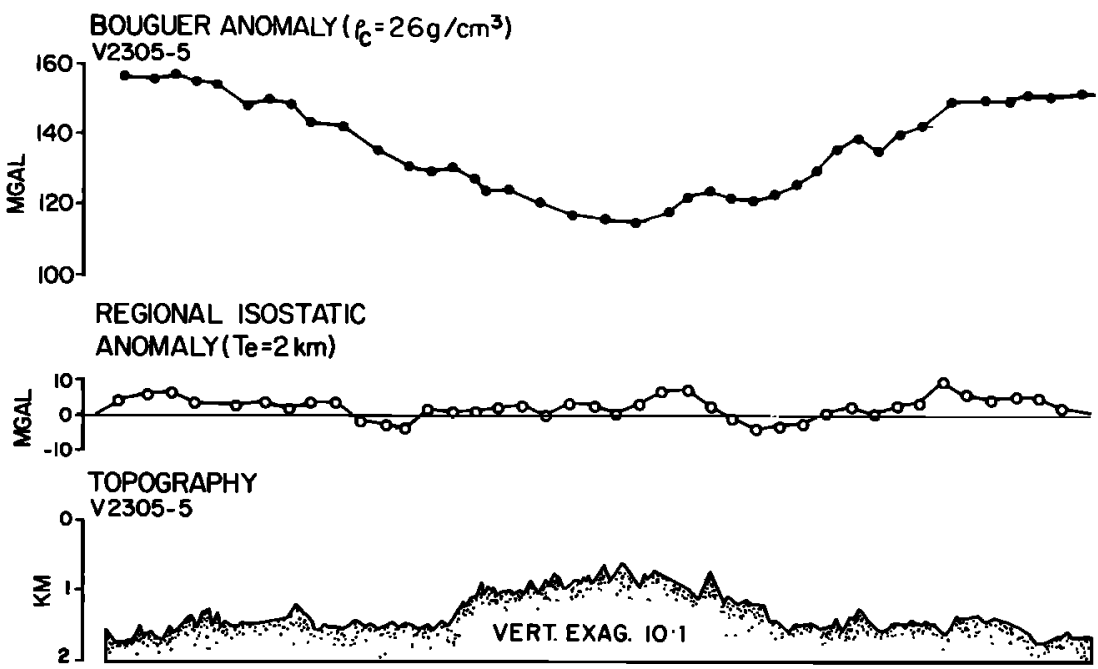

\section{MID-ATLANTIC RIDGE CREST (37.'N,FAMOUS)}

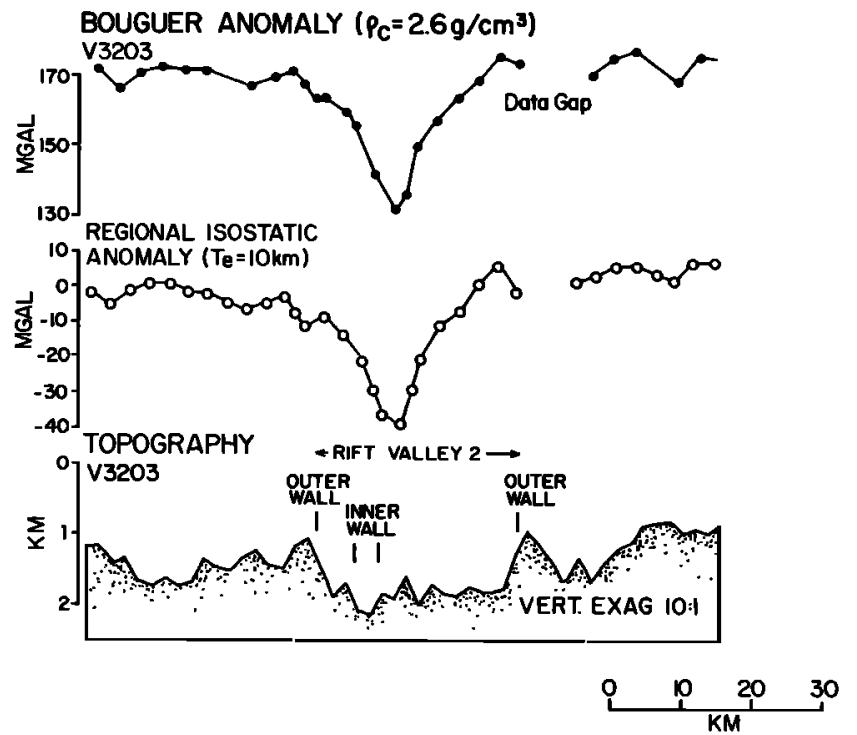

Fig. 15. Bouguer gravity anomaly and regional isostatic (plate model) gravity anomaly profiles over the Reykjanes Ridge at $61^{\circ} \mathrm{N}$ and the Mid-A tlantic Ridge at $37^{\circ} \mathrm{N}$. Note that although both profiles show a pronounced Bouguer anomaly low over the ridge crest, the regional isostatic anomaly profiles vary greatly. The Reykjanes $R$ idge crest is characterized by small regional isostatic anomalies, while the Mid-Atlantic ridge crest is characterized by a regional isostatic anomaly low of about $-30 \mathrm{mGal}$ over the rift valley. A regional isostatic gravity low characterizes the axial region of the Mid-Atlantic Ridge in both the North and South A tlantic. The Mid-Atlantic Ridge profile was chosen because it passes through the wellstudied Famous area. It was not used in generating the Mid-Atlantic Ridge filter (Figure 10) because it is not sufficiently long.

less than the values of $20-30 \mathrm{~km}$ determined from loads formed on older parts of the oceanic lithosphere [Watts and Cochran, 1974; Watts, 1978]. We attribute this difference to the origin of ridge topography in the axial portions of the ridge crests, where the lithosphere is hot and weak.

3. The difference in elastic plate thicknesses between the East Pacific Rise and the Mid-Atlantic Ridge appears to be real and significant and is interpreted as representing differences in the thermal structure of the region under the ridge crest. With the assumption that the effective elastic plate thick- ness represents the depth to a particular isotherm (taken to be $450^{\circ} \mathrm{C}$ ), the difference between the East Pacific Rise and the Mid-A tlantic Ridge can be explained as the result of differing spreading rates.

4. The Reykjanes Ridge results cannot, however, be easily explained in terms of spreading rate differences. The elastic plate thickness for this slow spreading (about $1 \mathrm{~cm} / \mathrm{yr}$ ) ridge is similar to that of the fast spreading $(>5 \mathrm{~cm} / \mathrm{yr}$ ) East Pacific Rise and appears to indicate anomalous thermal conditions beneath the $R$ eykjanes Ridge. 


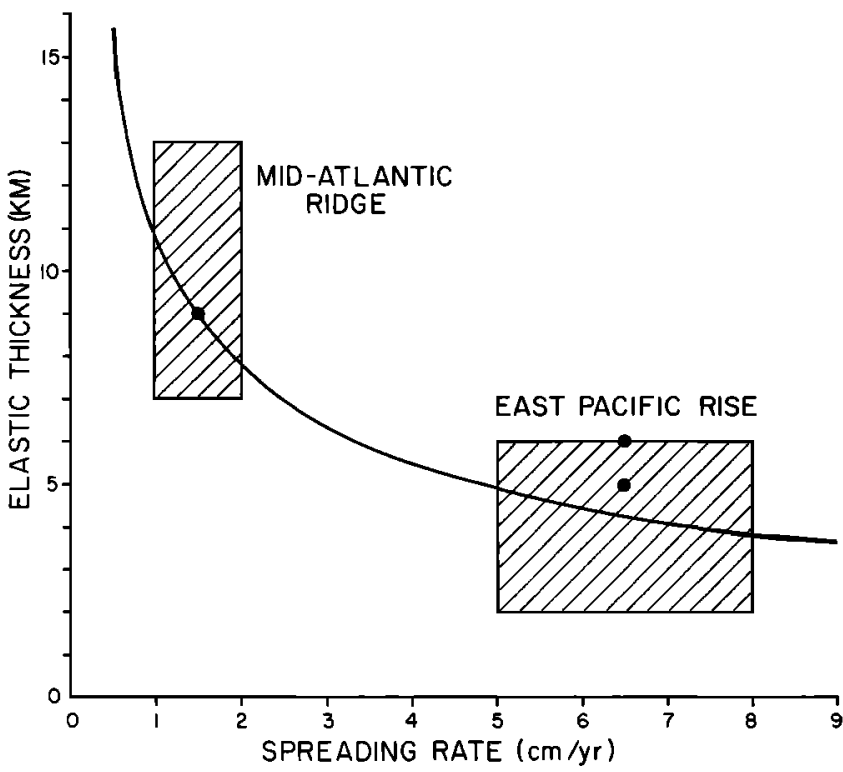

Fig. 16. Plot of the best fitting elastic thickness for the various ridge crests against the half spreading rate. The solid dots are the best fitting values, and the hatched boxes are subjective estimates of the possible range of the values based largely on the standard deviations of the admittance values (Figures 5 and 11 ). We also show a theoretical curve [Turcotte, 1974] calculated with the assumption that the base of the elastic lithosphere is the $450^{\circ} \mathrm{C}$ isotherm [Watts, 1978] and which is constrained to pass through the Mid-Atlantic Ridge value.

5. The presence of a positive (horst) or negative (rift valley) topographic feature at the ridge crest appears to be a function of the average temperature in the vicinity of the ridge crest. It is therefore a function of both the spreading rate and the temperature structure at the ridge crest.

6. Regional isostatic anomalies across ridge crests with axial highs are generally small, while those across ridge crests with axial rift valleys are larger and are characterized by a low over the axial rift valley. The isostatic gravity low over 'rifted' ridges can be as great as $20-30 \mathrm{mGal}$ and is usually confined to the vicinity of the rift valley. This result is interpreted as supporting models such as those of Sleep [1975], Sleep and Rosendahl [1979], and Lachenbruch [1973, 1976], in which viscous forces resulting from the interaction of the ascending magma and the conduit walls are considered the mechanism for producing ridge crest topography.

Acknowledgments. We would like to thank R. N. Anderson, M. G. Langseth, and J. K. Weissel for valuable comments and discussions. This research was supported by National Science Foundation grant OCE 77-07941. The data were gathered on cruises supported by the National Science Foundation and Office of Naval Research. Lamont-Doherty Geological Observatory contribution 2812.

\section{REFERENCE}

Anderson, R. N., and H. C. Noltimier, A model for the horst and graben structure of mid-ocean ridge crests based upon spreading velocity and basalt delivery to the oceanic crust, Geophys. J. Roy. Astron. Soc., 34, 137-147, 1973.

Arcyana, Transform fault and rift valley by bathyscaph and diving saucer, Science, 190. 108-116, 1975

Ballard, R. D., and T. H. Van Andel, Morphology and tectonics of the inner rift valley at lat. $36^{\circ} 50^{\mathrm{N}}$ on the Mid-Atlantic Ridge, Geol. Soc. A mer. Bull., 88, 507-530, 1977.

B ryan, W. B., and J. G. Moore, Compositional variations of young basalts in the Mid-Atlantic Ridge rift valley near $36^{\circ} 49^{\prime} \mathrm{N}$, Geol. Soc. Amer. Bull., 88, 556-570, 1977.
Cann, J. R., A model for oceanic crustal structure developed, Geophys. J. Roy. Astron. Soc., 39, 169-187, 1974.

Cochran, J. R., and M. Talwani, Free-air gravity anomalies in the world's oceans and their relationship to residual elevation, Geophys. J. Roy. Astron. Soc., 50, 495-552, 1977.

Deffeyes, K. S., The Axial Valley. A steady-state feature of the terrain, in The Megatectonics of Continents and Oceans, edited by H. Johnson and B. L. Smith, pp. 194-222, Rutgers University Press, New Brunswick, N. J., 1970.

Graf, A., and R. Schulze, Improvements on the sea gravimeter Gss2, J. Geophys. Res., 66, 1813-1821, 1961.

Handschumacher, D. W., Post-Eocene plate tectonics of the eastern Pacific, in The Geophysics of the Pacific Basin and Its Margin. Geophys. Monogr. Ser., vol. 19, edited by G. Sutton, M. Manghnani, and R. Moberly, pp. 177-202, AGU, Washington, D. C., 1976.

Heirtzler, J. R., and T. H. Van Andel, Project Famous: Its origin, programs and setting, Geol. Soc. A mer. Bull., 88, 481-487, 1977.

Herron, E. M., Sea floor spreading and the Cenozoic history of the east central Pacific, Geol. Soc. Amer. Bull., 83, 1671-1692, 1972.

Houtz, R. E., and J. I. Ewing, Upper crustal structure as a function of plate age, J. Geophys. Res., 81, 2490-2498, 1976.

Lachenbruch, A. H., A simple mechanical model for oceanic spreading centers, J. Geophys. Res., 78, 3395-3417, 1973.

Lachenbruch, A. H., Dynamics of a passive spreading center, $J$. Geophys. Res., 81, 1883-1902, 1976.

LaCoste, L. J. B., Measurement of gravity at sea and in the air., Rev. Geophys. Space Phys., 5, 477-526, 1967.

Ladd, J. W., G. O. Dickson, and W. C. Pitman, III, The age of the South A tlantic, in The Ocean Basins and Margins, vol. 1, The South Atlantic, edited by A. E. M. Nairn and F. G. Stehli, pp. 555-573, Plenum, New York, 1975.

Lambeck, K., Gravity anomalies over ocean ridges, Geophys. J. Roy. Astron. Soc., 30, 37-53, 1972.

Larson, R. L., and C. G. Chase, Late Mesozoic evolution of the western Pacific Ocean, Geol. Soc. Amer. Bull., 83, 3627-3644, 1972.

Le Pichon, X., J. Bonin, and J. Francheteau, Plate Tectonics, 300 pp., Elsevier, New York, 1973.

McDonald, K. C., and B. P. Luyendyk, Deep-tow studies of the structure of the Mid-A tlantic Ridge crest near lat. $37^{\circ} \mathrm{N}$, Geol. Soc. Amer. Bull., 88, 621-636, 1977.

M cK enzie, D. P., and C. Bowin, The relationship between bathymetry and gravity in the Atlantic Ocean, J. Geophys. Res., 81, 1903-1915, 1976.

Munk, W. H., and D. E. Cartwright, Tidal spectroscopy and prediction, Phil. Trans. Roy. Soc. London, Ser. A, 259, 533-581, 1966.

Needham, H. D., and J. Francheteau, Some characteristics of the rift valley in the Atlantic Ocean near $36^{\circ} 48^{\prime}$ north, Earth Planet. Sci. Lett., 22, 29-43, 1974.

Orcutt, J. A., B. L. N. Kennett, and L. M. Dorman, Structure of the East Pacific $R$ ise from an ocean bottom seismometer survey, Geophys. J. Roy. Astron. Soc., 45, 305-320, 1976.

Osmaston, M. F., Genesis of ocean ridge median valleys and continental rift valleys, Tectonophysics, II, 387-405, 1971.

Parker, R. L., The rapid calculation of potential anomalies, Geophys. J. Roy. Astron. Soc., 31, 447-455, 1972.

Parker, R. L., and D. W. Oldenburg, Thermal model of ocean ridges, Nature Phys. Sci., 242, 137-139, 1973.

Pitman, W. C., III, and M. Talwani, Sea-floor spreading in the North Atlantic, Geol. Soc. Amer. Bull., 83, 619-646, 1972.

Ramberg, I. B., and T. H. Van Andel, Morphology and tectonic evolution of the rift valley at lat $36^{\circ} 30^{\circ} \mathrm{N}$, Mid-Atlantic Ridge, Geol. Soc. A mer. Bull., 88, 577-586, 1977.

Rea, D. K., Model for the formation of topographic features of the East Pacific Rise Crest, Geology, 3, 77-80, 1975.

Rosendahl, B. R., Evolution of oceanic crust, 2, Constraints, implications, and inferences, J. Geophys. Res., 81, 5305-5314, 1976.

Rosendahl, B. R., R. W. Raitt, L. M. Dorman, L. D. Bibee, D. M. Hussong, and G. H. Sutton, Evolution of oceanic crust, 1, A physical model of the East Pacific rise crest derived from seismic refraction data, J. Geophys. Res., 81, 5294-5304, 1976.

Schilling, J.-G., Iceland mantle plume: Geochemical study of the Reykjanes Ridge, Nature, 242, 565-571, 1973.

Sclater, J. G., and J. Francheteau, The implications of terrestrial heat flow observations on current tectonic and geochemical models of the crust and upper mantle of the Earth, Geophys. J. Roy. Astron. Soc., 20, 509-542, 1970.

Sclater, J. G., R. N. Anderson, and M. L. Bell, Elevation of ridges and 
evolution of the central eastern Pacific, J. Geophys. Res., 76, 7888$7915,1971$.

Shor, G. G., H. W. Menard, and R. W. Raitt, Structure of the Pacific Basin, in The Sea, vol. 4, part 2, edited by A. E. Maxwell, pp. 3-28, Interscience, New York, 1970.

Sleep, N. H., Sensitivity of heat flow and gravity to the mechanism of sea-floor spreading, J. Geophys. Res., 74, 542-549, 1969.

Sleep, N. H., Formation of oceanic crust: Some thermal constraints, $J$. Geophys. Res., 80, 4037-4042, 1975.

Sleep, N. H., and S. Biehler, Topography and tectonics at the intersections of fracture zones with central rifts, J. Geophys. Res., 75. 2748-2752, 1970.

Sleep, N. H., and B. Rosendahl, Topography and tectonics of ridge axes, J. Geophys. Res., 84 in press, 1979.

Talwani, M., and O. Eldholm, Evolution of the Norwegian-G reenland Sea, Geol. Soc. Amer. Bull., 88, 969-999, 1977.

Talwani, M., B. C. Heezen, and J. L. Worzel, Gravity anomalies, physiography and crustal structure of the Mid-A tlantic Ridge, Publ. 22, pp. 81-111, Bur. Central Seismol. Int., Ser. A, Trav. Sci. Fasc. Int. Union of Geol. and Geophys., Paris, 1961.

Talwani, M., X. Le Pichon, and M. Ewing, Crustal structure of the mid-ocean ridges, 2, Computed model from gravity and seismic refraction data, J. Geophys. Res., 70, 341-352, 1965.

Talwani, M., C. C. Windisch, and M. G. Langseth, Reykjanes Ridge crest: A detailed geophysical study, J. Geophys. Res., 76, 473-517, 1971.

Talwani, M., H. R. Poppe, and P. D. Rabinowitz, Gravimetrically determined geoid in the western North A tlantic, Sea Surface Topography From Space, Tech. Rep. ERL-228-AOML 7-2, part 2, pp. 134, Nat. Oceanic and Atmos. Admin., Rockville, Md., 1972.

Turcotte, D. L., Are transform faults thermal contraction cracks?, J. Geophys. Res., 79, 2573-2577, 1974.

Van Andel, T. H., and C. Bowin, Mid-A tlantic Ridge between $22^{\circ}$ and $23^{\circ} \mathrm{N}$ latitude and the tectonics of mid-ocean rises, J. Geophys. Res., 73, 1279-1298, 1968.

Vening Meinesz, F. A., Gravity Expeditions at Sea. 1923-1938, vol. IV, 233 pp., Netherlands Geodetic Commission, Delft, 1948.

Vogt, P. R. The Iceland phenomenon: Imprints of a hot spot on the ocean crust, and implications for flow beneath the plates, in Geody. namics of Iceland and the North A tlantic A rea, edited by L. K rist jansson, pp. 105-126, D. Reidel, Hingham, Mass., 1974.

Walcott, R. I., Flexural rigidity, thickness and viscosity of the lithosphere, J. Geophys. Res., 75, 3941-3954, 1970.

Walcott, R. I., Lithospheric flexure, analysis of gravity anomalies, and the propagation of seamount chains, in The Geophysics of the Pacific Ocean Basin and Its Margin, Geophys. Monogr. Ser., vol. 19, edited by G. Sutton, M. Manghnani, and R. Moberly, pp. 431-438, AGU, Washington, D. C., 1976.

Watts, A. B., An analysis of isostasy in the world's oceans, 1, Hawaiian-Emperor Seamount Chain, J. Geophys. Res., 83, 5989-6004, 1978.

Watts, A. B., and J. R. Cochran, Gravity anomalies and flexure of the lithosphere along the Hawaiian-Emperor Seamount Chain, Geophys. J. Roy. Astron. Soc., 38, 119-141, 1974.

Watts, A. B., J. R. Cochran, and G. Selzer, Gravity anomalies and flexure of the lithosphere: A three-dimensional study of the Great Meteor Seamount, Northeast Atlantic, J. Geophys. Res., 80, 1391$1398,1975$.

Wing, C. G., MIT vibrating string surface ship gravity meter, $J$. Geophys. Res., 74, 5882-5894, 1969.

Woodside, J. M., The Mid-A tlantic Ridge near $45^{\circ} \mathrm{N}, \mathrm{XX}$, The gravity field, Can. J. Earth Sci., 9, 942-959, 1972.

(Received February 24, 1978;

revised May 18, 1978.

accepted January 8, 1979.) 